\title{
A GEOMORFologia Costeira E SEU DESDOBRAMENTO PARA A GEOGRAFIA COSTEIRA E MARINHA
}

Dieter Muehe

\author{
Universidade Federal do Rio de Janeiro - UFRJ
}

\section{Resumo}

A pesquisa geomorfológica costeira, no Brasil, vem crescendo de forma consistente e acelerada durante os últimos 80 anos, ajustando suas técnicas de pesquisa aos enormes avanços tecnológicos. O presente artigo analisa esta evolução, com foco nas principais linhas de pesquisa, ressaltando a participação de geógrafos, notadamente de geomorfólogos-geógrafos nesse desenvolvimento, além da evolução da própria Geografia, no sentido de ampliar o escopo da geomorfologia stricto sensu com vistas a integrá-la com aspectos socioeconômicos transitando, por fim, para a Geografia Costeira e a Geografia Marinha.

Palavras-chave: geomorfologia costeira, geografia costeira, geografia marinha, Brasil.
Abstract

Abstract Coastal geomorphic research in Brazil has been growing steadily and at an accelerated rate during the last eighty years, adjusting its research techniques to the enormous technological advances. This article analyzes this development focusing on the main lines of research, with a certain bias to emphasize the participation of geomorphologists with geographic background and its evolution in the sense of extending the scope of geomorphology stricto sensu to integrate with socioeconomic aspects and associated transition to Coastal and Marine Geography.

Key words: coastal geomorphology, coastal geography, marine geography, Brazil
Q uando Francis Ruellan (RUELLAN, 1944) publicou uma reconstituição da rede de drenagem fluvial preservada na morfologia do fundo da Baía de Guanabara, ressaltando a íntima relação entre morfologia, mudanças do nível do mar e paleoclima e, em seguida, Jean Tricart (TRICART, 1960) relacionou como origem principal dos depósitos arenosos costeiros a acumulação de areias provenientes da plataforma continental (tendo como origem secundária o aporte fluvial ou a erosão de falésias, como era considerado), foi estabelecida, de forma inequívoca, a dualidade de enfoque e integração entre processos morfossedimentares de ambientes emersos e submersos na origem da morfologia de feições costeiras.

A própria localização de contato entre terra emersa e submersa, forçosamente coloca a Geomorfologia Costeira em posição periférica à Geomorfologia, o que se reflete em tratamento periférico na literatura geomorfológica a ponto de, em muitos livros de Geomorfologia e Geografia Física, a especialidade costeira não ser mencionada. 
A dualidade de enfoque é uma característica da Geomorfologia Costeira, amplamente representada na compartimentação regionalizada do litoral brasileiro de João Dias da Silveira (SILVEIRA, 1964), quando este relaciona aspectos morfológicos climáticos e oceanográficos em uma classificação que vem servindo de referência para outras classificações que, na maioria das vezes, apenas se diferenciam por pequenos ajustes de enfoques ou pelo maior detalhamento decorrente das informações disponíveis.

As formações arenosas, quando em forma de barreiras ou cordões litorâneos, são denominadas de restingas, e foram associadas pioneiramente por Adalberto Ribeiro Lamego (LAMEGO, 1940, 1945) ao transporte via correntes oceânicas na forma de pontais, levando ao fechamento progressivo de enseadas e a sua transformação em lagunas ou lagoas costeiras, em modelo aplicado especificamente à Região dos Lagos no litoral do Rio de Janeiro. Apesar dessa teoria ter sido rejeitada posteriormente, representava o pensamento dominante na época.

Trabalhos pioneiros, que foram e continuam sendo fundamentais para compreendermos a evolução da morfologia costeira brasileira - principalmente das barreiras arenosas - foram a reconstituição das variações do nível do mar nos últimos 7 mil anos, iniciadas por Martin (MARTIN et al. 1978), Suguio (SUGUIO; MARTIN, 1981; SUGUIO et al. 1985), aos quais se seguiram outros trabalhos que levaram a ajustes importantes, tais como os realizados por Steven Ireland (IRELAND, 1987; ÂNGULO; LESSA, 1997), a caracterização evolutiva dos deltas ou planícies costeiras deltiformes (MARTIN; FLEXOR, 1987) e, ainda, a mudança de direção de cristas de praia das planícies deltaicas como reflexo de mudança de direção de incidência das ondas, e sua relação com El Niño-La Niña, já sinalizando a relação de efeitos climáticos de larga escala sobre os processos costeiros (MARTIN et al. 1984).

$\mathrm{Na}$ caracterização granulométrica de depósitos arenosos de praias e dunas, são notórios os trabalhos pioneiros de Martins (1967) e Bigarrella (BIGARELLA et al. 1969) ao empregarem a análise estatística das distribuições granulométricas com o emprego da escala fi $(\Phi)$ de Krumbein (1934), conforme proposto por Folk $(1957,1974)$ e largamente adotado no Brasil, em trabalhos subsequentes de caracterização granulométrica dos depósitos sedimentares, seu transporte, e sua interpretação ambiental Xavier-da-Silva (1973a), Bittencourt (BITTENCOURT et al. 1992) e outros

As investigações acadêmicas em Geomorfologia Costeira somente tomaram impulso na segunda metade do século XX, após a reforma universitária de 1968, com ampliação das oportunidades de dedicação exclusiva dos docentes, e a criação dos programas de pós-graduação. Essa evolução é bem demonstrada pelo aumento do número de trabalhos sobre praias publicados em revistas ou anais de congressos, os quais apresentaram, inicialmente, incremento na segunda metade da década de 1970, associado em parte ao retorno dos docentes após concluírem pósgraduação. Posteriormente, houve novo incremento da produção, dessa vez de forma exponencial partir da segunda metade da década de 1990 (Figura 1). 


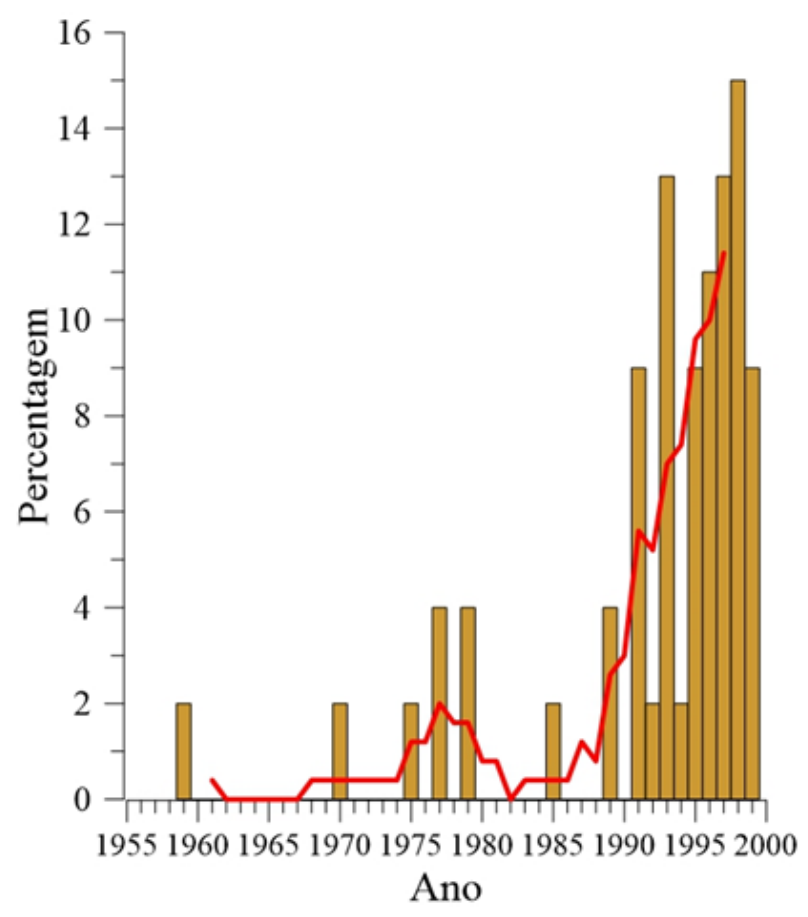

Figura 1. Evolução quantitativa da produção científica sobre praias, expresso em relação ao total de trabalhos publicados em geologia marinha (Muehe, 2003).

Essa expansão vem se mantendo, apesar da redução, entre 2011 a 2015, da hegemonia dos estudos costeiros (SALGADO; LIMOEIRO, 2017) em relação ao período de 2001 a 2005 (SALGADO; BIAZINI; HENNIG, 2008), quando então a Geomorfologia Costeira e Submarina ocupava o segundo lugar em número de publicações, logo após a Geomorfologia Fluvial, com destaque para a Universidade Federal do Rio de Janeiro. Num segundo levantamento, para o período de 2006 a 2010 (OLIVEIRA; SALGADO, 2013) a Geomorfologia Costeira perdeu sua expressão em publicações nacionais, mas se destacou em número de trabalhos em revistas internacionais, com mais que o dobro sobre o segundo colocado, que foi a Geomorfologia Fluvial. Nesses levantamentos não foram consideradas revistas importantes para a Geomorfologia Costeira, tais como Marine Geology, Journal of Coastal Research, e Revista da Gestão Costeira Integrada (Journal of Integrated Coastal Management) o que pode ter distorcido o resultado.

\section{Classificações do litoral}

As primeiras classificações do litoral brasileiro remontam à primeira metade do século $X X$, através de autores como Gabaglia, (1916) e Carvalho (1926), conforme Diniz e Carvalho (2017), baseando-se o primeiro em aspectos predominantemente morfológicos ou sedimentares, com a identificação de seis macrocompartimentos, enquanto o segundo se baseou em características geológicas, principalmente a idade, com a identificação de quatro macrocompartimentos. $\mathrm{O}$ trabalho de maior expressão, amplamente aceito, foi elaborado por Silveira (1964), que identificou cinco regiões geográficas: Norte, Nordeste, Leste ou Oriental, Sudeste e Sul. Estas, por sua vez, subdividi- 
das em macrocompartimentos segundo características climáticas, oceanográficas e topográficas. É na subdivisão que as opiniões nem sempre coincidem, mas no geral há um razoável consenso com relação aos limites adotados.

A compartimentação do litoral sul-americano, baseada na configuração morfométrica da linha de costa, foi apresentada por Xavier-da-Silva (1973) que, no litoral do Brasil, coincidiu com outros limites para diferentes compartimentos, estabelecidos posteriormente por diversos autores empregando critérios variados Palma (1979), França (1979), Schaeffer-Novelli (SCHAEFFERNOVELLI et al. 1990), Villwock (1994). Este último, baseado na compartimentação de Silveira (1964), passa a detalhar o arcabouço geológico e a descrever detalhadamente os processos de transporte sedimentar, a formação de feições deposicionais costeiras, e o efeito das transgressões e regressões marinhas.

Subsequentemente, Muehe (1998), ainda com base na compartimentação de Silveira (1964), mas com a identificação de maior número de compartimentos, apresenta uma explicação sobre os critérios utilizados na definição dos limites de cada um daqueles, junto com a descrição de suas características geomorfológicas, oceanográficas e sedimentares, com a inclusão da plataforma continental interna.

Trabalhos posteriores continuam influenciados pela classificação de Silveira (1964), mas passam a focar orientações distintas, enfatizando mudanças do clima, caracterização geológica, fitogeográfica, climática, ou vulnerabilidade erosiva. Muehe (1998; 2005; 2006a; 2009; 2010), Muehe e Neves (1995), Ab’Sáber (2000), Dominguez (2004, 2007, 2009), entre outros.

Nesse sentido, Domiguez (2007; 2009) apresenta uma classificação tipológica com ênfase no conjunto de condicionantes como tectônica, geologia, circulação aérea e oceânica, e transporte de sedimentos, com a identificação dos compartimentos segundo suas características dominantes, seja geomorfológica-oceanográfica (tidal embayment of the Amazon), oceanográficamorfológica (dip-fed wave dominated deltaic coast of Eastern Brazil), morfológica (high relief coast of Southeastern Brazil), ou sedimentar (sediment starved coast ot Northeastern Brazil e strike-fed sandy coast of Rio Grande do Sul).

A partir dos vários trabalhos citados é apresentada uma denominação específica para os diferentes macrocompartimentos, que continuarão a sofrer alterações de denominação e limites de acordo com os novos conhecimentos e as novas maneiras de enfatizar essa ou aquela peculiaridade ambiental ou de uso (Figura 2).

Mais recentemente, Diniz e Oliveira (2016) e Diniz et al. (2016) subdividiram a região litorânea do Nordeste em duas regiões: a Costa Semiárida Brasileira, e a Costa dos Recifes, com subdivisões de maior resolução a partir da influência da configuração da linha de costa (convexidade ou concavidade), seu efeito no fluxo eólico e, consequentemente, no grau de aridez ou umidade. Além dessa, destaca-se a classificação geomorfológica de costões rochosos para o litoral do estado do Rio de Janeiro, proposta por Farias (2018). 


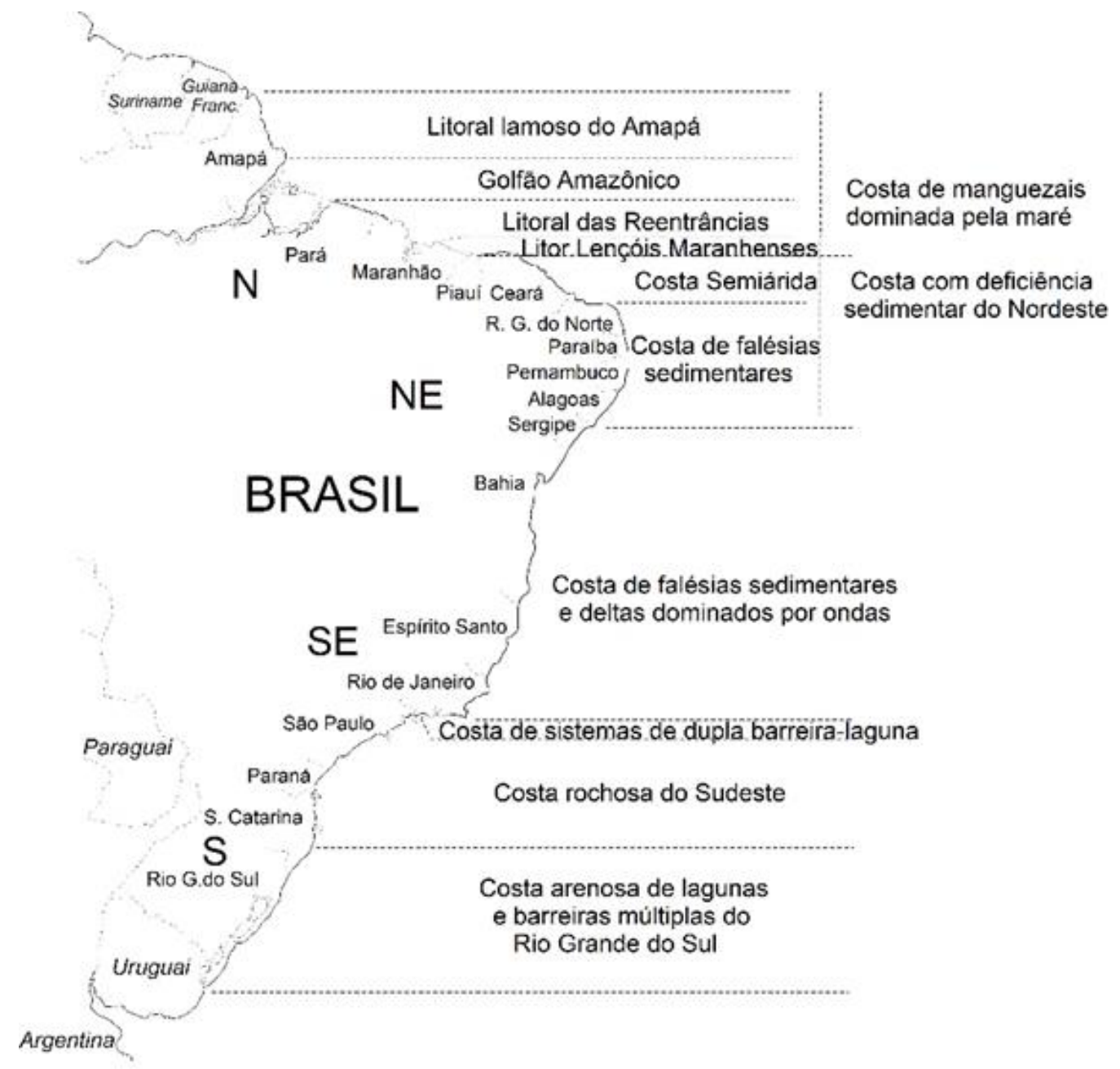

Figura 2. Compartimentação geomorfológica do litoral (modificado de Muehe [2009; 2010]).

\section{Modelos morfossedimentares}

\section{Cordões litorâneos (barreiras arenosas)}

Os cordões litorâneos, ou barreiras arenosas, são acumulações sedimentares relativamente estreitas e muito longas, localizadas em contato direto com a praia ou na forma de paleo-cordões mais interiorizados, deixados para traz à medida que a linha de costa avançou em consonância com as flutuações do nível do mar, sendo sua largura e altura reflexo da disponibilidade de sedimentos, da altura do nível marinho, e da energia das ondas, podendo ainda sua altura ser posteriormente aumentada pela acumulação de depósitos eólicos. 
No litoral brasileiro sua ocorrência mais comum é na forma de barreiras simples ou duplas, e, ainda, na forma de múltiplos cordões no estado do Rio Grande do Sul, devido à baixa declividade da planície costeira que ali favorece a alta resolução espacial, em resposta às oscilações do nível marinho. Uma caracterização das barreiras holocênicas ao longo do litoral brasileiro pode ser encontrada no livro Geology and Geomorphology of Holocene Coastal Barriers, organizado por Sergio R. Dillenburg e Patrick A. Hesp (DILLENBURG; HESP, 2009).

Lamego $(1940,1945)$ apresentou um modelo de interpretação da evolução das barreiras arenosas litorâneas, atribuindo a formação dos cordões litorâneos da vertente sul do litoral do estado do Rio de Janeiro, desde a Baía de Sepetiba com a restinga da Marambaia, à Lagoa de Araruama com a restinga da Massambaba, ao fechamento gradual das enseadas por cordões litorâneos, sendo esse processo decorrente do transporte longitudinal de sedimentos em direção à leste, ou seja, em direção ao Cabo Frio, tendo denominado estes cordões de restingas.

Foi somente a partir dos trabalhos de Coe Neto (1984), Muehe (1984), Turcq (TURCQ et al. 1999) e, mais detalhadamente, de Muehe e Correa (1989), que mudou a interpretação dessa evolução, no sentido de rejeitar o modelo de progradação lateral na forma de um pontal, a favor de um modelo de migração retrogradacional em consonância com a elevação do nível do mar, justificado, notadamente, pela ausência de transporte longitudinal residual capaz de formar um pontal, pela existência de mais de um cordão de altura e idade diferentes, e pela presença de arenitos de praia submersos, atestando a posição pretérita dos cordões arenosos e sua posterior retrogradação.

Neste sentido, a denominação "restinga", como atribuído acima, a um processo de progradação lateral (coastwise spit progradation), conforme Swift (1986) era, na realidade, predominantemente, o resultado de um processo de migração retrogradacional (mainland beach detachment) (SWIFT, 1986) associado à elevação do nível do mar, e inundação da área à retaguarda, segundo o modelo de Hoyt (1967), à medida que o nível do mar continuava subindo, levando à formação de lagunas ou lagoas costeiras, dependendo da subsequente conexão ou não com o mar.

Com as diversas interpretações do conceito de restinga, gerando dúvidas de quanto à sua origem, o termo passou a ser empregado para todos os depósitos arenosos de origem marinha que possuam determinadas características sedimentológicas e fitofisionômicas, perdendo-se a ligação à gênese da feição geomorfológica existente.

A idade dos duplos cordões do Rio de Janeiro e, por extensão, de outros depósitos semeIhantes, foi por muito tempo associada às oscilações holocênicas do nível do mar, seja pela diferença de altura entre essas, ou por ser o mais interiorizado, o mais antigo e mais alto e, ainda, pelas datações obtidas até então. Apenas com os resultados das análises estratigráficas de Steven Ireland (1987) em depósitos arenosos nas proximidades do município de Niterói, no estado do Rio de Janeiro que foi definida a idade pleistocênica do cordão litorâneo mais antigo, mais tarde também confirmada por Martin e Suguio (1989).

Um trabalho abrangente sobre as barreiras arenosas no Brasil foi organizado por Sergio Dillenburg e Patrick Hesp (DILLENBURG; HESP, 2009). 


\section{Praias}

As praias e todos os depósitos sedimentares são, em geral, caracterizados por sua extensão, forma, mobilidade, estrutura e granulometria. Ainda estudante, me interessei por compreender essa última característica, através de parâmetros das distribuições granulométricas das diferentes feições praiais. O método de estudo consistia em peneirar as amostras através de um conjunto de peneiras de malhas decrescentes, onde são lançados os pesos das amostras retidas em cada peneira, obtendo-se o peso total da amostra, exposto em percentagem num gráfico de probabilidade aritmética.

A partir daí, eram retirados os diâmetros correspondentes a determinados percentuais, para serem introduzidos num conjunto de equações, com objetivo de determinar a média, a mediana, o desvio padrão, e a assimetria da respectiva distribuição, conforme proposto por Folk (1957, 1974). Nesse tipo de gráfico, uma distribuição normal é representada por uma reta. A grande vantagem reside no fato do eixo das abcissas ser exposto em escala aritmética, no lugar da escala logarítmica, como nas representações tradicionais, permitindo uma correta interpolação. Os valores expressos em fi $(\phi)$, correspondem ao logaritmo negativo de base 2 do valor em milímetro $(\phi=$ - $\log 2 \mathrm{~mm}$ ), o que transforma uma progressão geométrica numa progressão aritmética. Assim, as areias ficavam num intervalo de $0 \phi$ a $4 \phi$ subdivididos em intervalos inteiros de $1 \phi$ entre as diversas classes de texturas (areia grossa, média, fina e muito fina) com o valor em $\phi$ aumentando conforme a diminuição do tamanho do grão.

Esse método facilitava muito a identificação dos diferentes ambientes de deposição, a inferência de direção de transporte residual, e a comparação entre amostras. Na época (década de 1960), porém, não havia computador e era tedioso calcular os parâmetros granulométricos de cada amostra. Também só dispúnhamos de um vibrador de peneira manual, o que ocasionava um barulho ensurdecedor que impedia seu uso durante o período de aulas. Com a chegada das primeiras máquinas eletrônicas de calcular - inicialmente com apenas uma memória - os cálculos começaram a ficar menos tediosos, mas foi só com a introdução do computador que tudo ficou mais fácil, permitindo inclusive a realização de análises mais sofisticadas de classificação, de direção de transporte, de agrupamento, e de mapeamento espacial das distribuições. Para isso, primeiramente foi utilizado o programa "SYMAP" e, posteriormente, com um número crescente de outros programas, tais como "Microsoft Excel", "Grapher", e "Surfer" da empresa Golden Software, os quais continuam sendo oferecidos em versões cada vez mais aprimoradas e amigáveis, até os programas de informação geográfica ("ArcGis", "Global Mapper", "Springer", "SAGA", entre outros).

Já no tocante à morfologia da praia e sua dinâmica, inicialmente os trabalhos consistiam, em sua maioria, de perfis topográficos transversais à praia, tanto individuais - geralmente no cento do arco praial - quanto em algumas posições ao longo do arco ou mesmo agrupados na tentativa de obter uma representação tridimensional. Nesses primórdios, os levantamentos terminavam na base da face da praia, no local de refluxo máximo da onda, mas foram, com o tempo, se estendendo cada vez mais para a zona de surfe e para além, buscando caracterizar a chamada antepraia (shoreface) até a sua profundidade de fechamento onde a variabilidade topográfica do fundo, por efeito das ondas, se torna muito pequena. A caracterização citada prossegue, inclusive, 
e mais adiante, em maiores profundidades, com a acoplagem de levantamento topográfico com ecobatimetria realizada por embarcações de pequeno porte, como botes infláveis e traineiras, e mesmo caiaques em áreas muito rasas (MUEHE, 2004; BELLIGOTTI; MUEHE, 2012). Ocorreu, assim, gradativamente, a incorporação do fundo marinho aos levantamentos de praias.

No que tange aos levantamentos de perfis de praia, tudo indica que o primeiro foi realizado em Pernambuco, na Praia da Piedade (OTTMAN et al. 1959), com o objetivo de correlacionar a topografia da praia com a granulometria e a concentração de carbonatos. Não chegou a monitorar a mobilidade topográfica da praia, nem associar a mesma à energia das ondas, apesar de ter sido esse o objetivo inicial (MUEHE, 2003). A relação da dinâmica da praia com eventos meteorológicos e oceanográficos, foi tratada, de modo pioneiro, no trabalho de Renato Kowsmann (1970), ao monitorar uma sequência de perfis sazonais na praia de Copacabana, ainda antes da realização do aterro de alargamento da mesma. Empregou para esse fim o método das balizas de Emery (1961) que, com a ajuda de duas balizas, tendo o horizonte como referência, permite levar o perfil topográfico até um pouco além do refluxo das ondas. Foi, assim, o introdutor deste método no Brasil, um processo simples e de baixíssimo custo, com precisão suficiente para realizar este tipo de levantamento, que passou a ser amplamente empregado no país.

Vale ainda registrar um trabalho de grande envergadura, praticamente desconhecido no Brasil (MUEHE, 2003), sobre morfodinâmica de praia e fundo marinho adjacente, realizado em segmento costeiro ao sul de Aracaju, no estado de Sergipe, imediatamente ao norte da desembocadura do rio Vaza Barris, por encomenda da PETROBRAS. Consistiu tal empreitada no monitoramento topográfico de um conjunto de perfis paralelos, em uma praia dissipativa, que se estendeu da praia à antepraia, juntamente com medições de parâmetros oceanográficos e meteorológicos (SUHAYDA et al. 1977). Fazia parte dessa equipe o Professor Andrew Short que, mais tarde, juntamente com L. D. Wright, (WRIGHT; SHORT, 1984), aplicou o parâmetro $\Omega$ de previsão do estado morfodinâmico em praias a partir dos dados laboratoriais obtidos por Gourlay (1968), sendo tal parâmetro definido pelo diâmetro mediano dos sedimentos da face praial, da altura da onda na arrebentação, e do período da onda.

Trabalhos pioneiros foram realizados na Universidade Federal do Rio de Janeiro (MUEHE, 1975, 1979) e (MUEHE; DOBEREINER, 1977), este último, aproveitando a estrutura do píer de apoio à construção de um emissário submarino na praia de Ipanema, permitiu monitorar o perfil topográfico e granulométrico da praia e da antepraia sob variadas condições de energia de onda.

No Brasil, trabalhos pioneiros com adoção da classificação morfodinâmica de praias foram realizados simultaneamente por Calliari e Klein (1993) e Toldo (TOLDO et al. 1993). O método foi largamente empregado na caracterização de praias, entretanto, pela sua tendência a prever o estado morfodinâmico que a praia, em tese, atingiria após alguns dias - desde que mantidas as condições oceanográficas observadas -, foi proposto um método alternativo para determinar, no momento da observação, o estado morfodinâmico da praia, que leva em consideração a dispersão de energia na zona de surfe, por meio da diferença obtida entre a altura da onda na arrebentação, e pelo espraiamento na face da praia (MUEHE, 1998).

Enquanto o perfil de equilíbrio da praia na sua porção submarina - ou seja, da antepraia superior - era estabelecido de forma empírica em função do diâmetro granulométrico mediano da face da praia (DEAN, 1977), a avaliação do equilíbrio em planta era menos difundida. Ajustes, 
seja empregando a espiral logarítmica (YASSO, 1965; CARVALHO; CLAUDINO-SALES, 2017), a parabólica (HSU et al. 1987), ou a tangente hiperbólica (MORENO; KRAUS, 1999), apesar de conhecidos, eram pouco aplicados no país. No entanto, foi a partir da disponibilização do programa MEPBAY do ajuste parabólico de Hsu (HSU et al. 1987), de uso simples (VARGAS et al. 2002), que o método teve aplicação mais ampla (KLEIN et al. 2003; SILVEIRA et al. 2010; ALBINO et al. 2016; BARRETO et al. 2016, entre outros).

O citado programa, após alguns aperfeiçoamentos e mudanças, deixou de ser disponibilizado e as últimas atualizações não funcionam nas versões mais recentes do Windows. Uma alternativa é empregar os programas disponibilizados pelo Sistema de Modelagem Costeira (SMCBrasil), desenvolvidos na Universidade de Cantábria, em aplicação no Brasil através de convênio com o Ministério de Meio Ambiente. Uma comparação entre os dois programas é apresentada por Raabe (2010).

Um trabalho abrangente, com a descrição científica das praias oceânicas brasileiras, realizado pelos diversos grupos de pesquisa ao longo do litoral, foi organizado por Andrew D. Short e Antonio H.F. Klein (SHORT; KLEIN, 2016).

\section{Dunas}

De carona para o Rio de Janeiro num avião da Força Aérea Brasileira, após uma excursão ao Amapá e Pará em 1964, quando estudante de graduação na Universidade do Brasil (atual UFRJ), estávamos jogando cartas para passar o tempo, sentados em torno de uma mala usada como mesa, quando me levantei para olhar pela janelinha da porta. O que vi me deixou maravilhado e perplexo. Parecia que estávamos sobrevoando um deserto. Um campo de dunas se estendia a perder de vista. Os aviões não voavam na altura que é hoje o padrão de modo que a abrangência espacial não era tão ampla. Eram os Lençóis Maranhenses. Foi meu primeiro contato com dunas.

Dunas ocorrem preferencialmente em regiões de clima seco, vento forte e areias de granulometria fina. Condições encontradas do sul do Maranhão ao Rio Grande do Norte. Não obstante, mesmo em locais de clima úmido, no sul do Brasil, como no estado do Rio Grande do Sul, ocorrem campos de dunas expressivos, conforme mostram os trabalhos de Tomazelli, (1990, 1993, 1994), Hesp (HESP et al. 2005), entre outros, e em Santa Catarina, onde Bigarella analisa as estruturas no campo de dunas das Duna da Lagoa (BIGARELLA, 1979; BIGARELLA et al. 1969), a morfologia e estrutura de uma duna parabólica (BIGARELLA, 2000), e Vintem analisam o efeito da granulometria no transporte eólico e desenvolvimento de campos de dunas transgressivas (VINTEM et al. 2006). Em suma, com disponibilidade de sedimentos com granulometria adequada e vento persistente, ocorrem dunas em quase todos os estados brasileiros, se não na forma de campos de dunas mais extensos, pelo menos na forma de dunas frontais.

Afinal, mesmo em locais chuvosos, bastam alguns dias de tempo seco para que o processo eólico se estabeleça, desde que o vento tenha velocidade suficiente para o transporte das areias. Exemplos mais localizados ocorrem no estado do Rio de Janeiro, desde a Restinga da Marambaia à Região dos Lagos, nas proximidades do município de Cabo Frio, e ao redor da desembocadura do rio Paraíba do Sul. Mais especificamente, na região entre os municípios de Arraial do 
Cabo e Armação dos Búzios, aparecem campos de dunas transgressivas bem extensos que, em Cabo Frio, frequentemente avançam sobre a rodovia, dificultando a passagem de carros. Na região da praia do Peró, região norte de Cabo Frio, ocorrem campos de dunas frontais e dunas transgressivas separados por uma planície de deflação com dunas parabólicas semi-estabilizadas (MUEHE et al. 2010, MOULTON et al.2013), tendo Fernandez descrito geomorfologicamente as dunas de toda a área considerada (FERNANDEZ et al. 2017). Já Dourado e Silva (2005) e Castro (2005) apresentaram monitoramento do deslocamento da frente distal do campo de dunas do Peró. No estado do Espírito Santo, na região de Itaúnas, o deslocamento de uma duna, após retirada da vegetação, recobriu todo um povoado e se transformou num ponto de atração turística.

Os maiores campos de dunas, naturalmente, se desenvolvem nas áreas de maior aridez dos estados do Maranhão ao Rio Grande do Norte, desde os Lençóis Maranhenses até as dunas barcanas gigantes de Jericoacoara, no estado do Ceará.

No estado do Maranhão, uma classificação preliminar das dunas dos Lençóis Maranhenses é apresentada por Gonçalves (GONÇALVES et al. 2003). Há estudo realizado em perfis num campo de dunas transversas, nos Lençóis Maranhenses, para avaliações morfométricas de controle do espaçamento entre as dunas (PARTELI et al. 2006) e, numa tese de doutorado, Jorge Hamilton S. dos Santos (2008), analisa o referido campo de dunas por meio de sensoriamento remoto, e através de descrição paisagística (SANTOS; SANTOS, 2015).

No Ceará, ao contrário do Maranhão, onde são escassos os dados sobre vento e ondas, o número de trabalhos, tanto descritivos como metodológicos, é significativo. Assim, Jimenes (JIMENES et al. 1999) descreve sobre a migração das dunas ao longo do litoral do Ceará, TSOAR (TSOAR et al. 2009) relaciona a estabilidade ou mobilidade das dunas costeiras às mudanças do clima, Sauermann (SAUERMANN, et. al. 2003) analisa a velocidade do vento e o transporte de areia numa duna barcana, e Carvalho (CARVALHO et al. 2004) relaciona a deriva litorânea ao potencial de formação de dunas, enquanto Maia (MAIA et al. 2005) relaciona o incremento de transporte eólico e de migração de dunas ao efeito El Niño, Meireles (2011) analisa a velocidade de migração de dunas móveis de Jericoacoara, e Castro (2005) relata o soterramento devido à migração de uma duna transversal em Paracuru. Em outro trabalho, Alexandre M. Carvalho (CARVALHO et al. 2016), analisa a relação entre a direção do vento, e a linha de costa, na mobilização de dunas de areia em dois segmentos de orientação distinta do litoral cearense. Uma análise faciológica e estrutural dos depósitos eólicos costeiros do oeste do Ceará foi realizada por Mesquita (MESQUITA et al. 2016).

O primeiro simpósio brasileiro sobre dunas, realizado em conjunto com o Simpósio Internacional sobre Dunas costeiras, ocorreu em 2005 na cidade de Fortaleza, organizado por Luís Parente Maia e colaboradores do LABOMAR - Instituto de Ciências do Mar, da Universidade Federal do Ceará (KLEIN; MAIA, 2008).

\section{Inferências paleoclimáticas}

Um dos primeiros artigos sobre inferências paleoclimáticas no Brasil se deve ao trabalho de Bigarella e Salamuni, a partir da medição de estratificações cruzadas em dunas nos arenitos Botucatu, 
reconstituindo as direções predominantes do vento naquele período (BIGARRELLA; SALAMUNI, 1961). Devido à quantidade de medições realizadas da direção e de mergulho dos estratos, o primeiro autor desenvolveu um equipamento para facilitar a medição desses parâmetros, o qual denominávamos de "Bigarelômetro". O trabalho não era costeiro no sentido estrito, mas era de interesse geral, e já direcionava o estudo para a reconstituição de paleoclimas, ao qual seguiu-se trabalho sobre a mesma temática (BIGARELLA et al. 1969). Mudanças na direção de cristas de praia nas planícies costeiras (Figura 3), foram associadas a inversões da direção de transporte litorâneo (longshore) durante os últimos 7 mil anos. Essas inversões foram, na planície costeira do Rio Doce (RJ), relacionadas por Martin, (MARTIN et al. 1993) a eventos El Niño. Em outro trabalho, Dominguez (DOMINGUEZ et al 1994), também associa a reversão de sentido da deriva litorânea na planície costeira do rio Doce às mudanças no padrão de circulação atmosférica como sendo resultante do bloqueio dos ventos alísios de leste-sudeste, mediante deslocamentos latitudinais na célula de alta pressão do Atlântico Sul. Associam, ainda, as alternâncias no aporte sedimentar em dunas na praia de Atalaia, no estado do Piauí, às mudanças na precipitação atmosférica ligada à Zona de Convergência Intertropical em escala decadal.

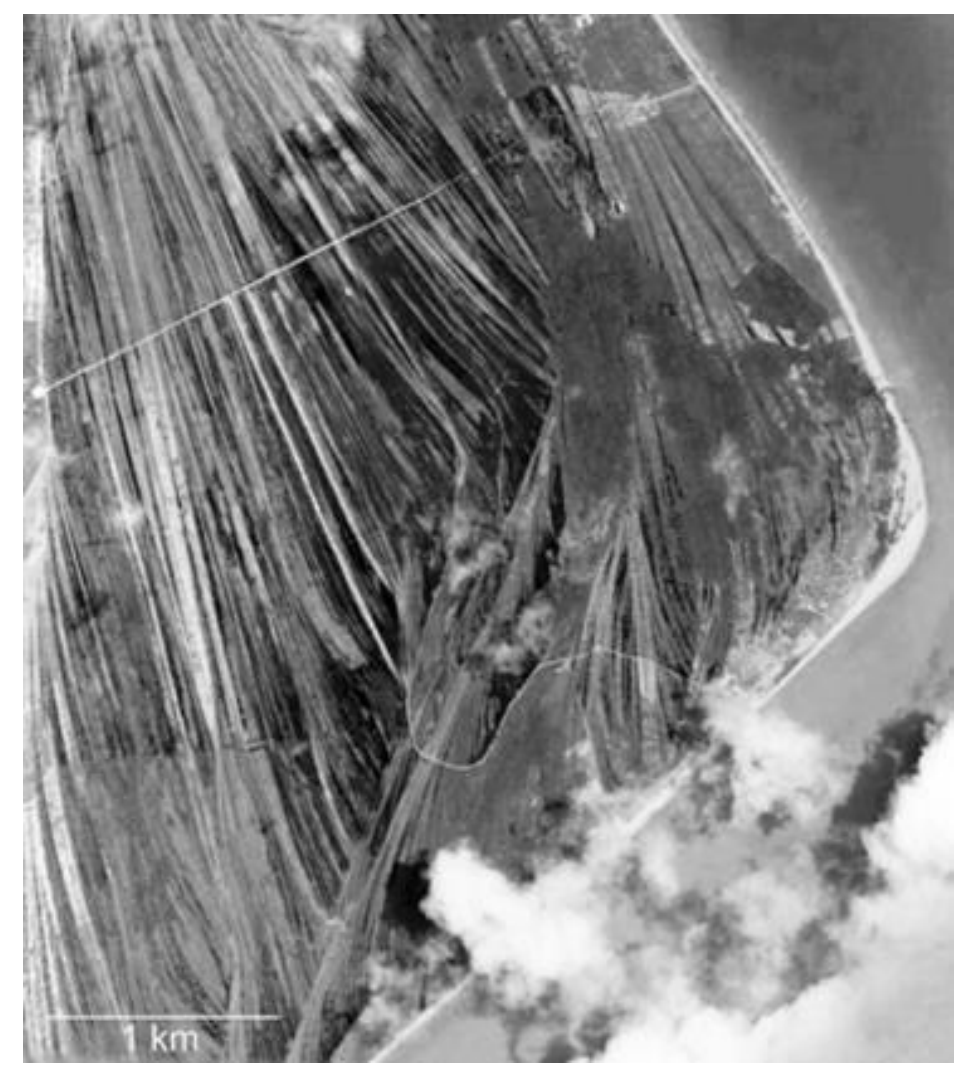

Figura 3. Planície de cristas de praia de Caravelas (BA) como exemplo de diferentes alinhamentos de feixes de restinga. Imagem Google Earth.

A descoberta da importância da deriva litorânea na evolução das planícies deltiformes estas associadas às desembocaduras dos rios São Francisco, Jequitinhonha, Doce, e Paraíba do 
Sul (DOMINGUEZ et al. 1981) - foi um marco, tanto que a construção das planícies estaria mais associada ao acréscimo de areias marinhas, em detrimento dos sedimentos fluviais (DOMINGUEZ et al. 1982; DOMINGUEZ, 1990). Outro momento notável na compreensão das alternâncias de processos geomorfológicos, associados às mudanças climáticas quaternárias, foi a publicação dos trabalhos sobre as linhas de seixos e depósitos correlativos, e sua associação com as mudanças do clima para mais seco durante os períodos glaciais (CAILLEUX, 1957; AB'SÁBER, 1962; BIGARELLA, 1964; BIGARELA et al. 1965; AB'SÁBER, 1977, entre outros). Por oportuno, vale ainda mencionar dois trabalhos de reconstituição da morfologia costeira: um sobre a evolução do relevo a leste da Baía de Guanabara, Muehe (1983), e outro sobre a evolução da planície costeira da Baía de Vitória (MACHADO et al. 2018).

Foi de fundamental importância para os estudos costeiros a reconstituição da variação relativa do nível do mar na porção central do litoral brasileiro para os últimos 7 mil anos. A definição desta curva de variação foi essencialmente devida aos trabalhos de Martin (MARTIN et al. 1979) para o litoral ao norte Salvador, onde foi feita a reconstituição mais completa, seguida de outros trechos do litoral brasileiro, tendo como referência a configuração da curva de Salvador (SUGUIO et al. 1985; MARTIN et al. 2003; entre outros). Para que as datações pudessem ser feitas nas quantidades necessárias, foi decisiva a implantação de um laboratório para datação por Carbono 14 (C14) na Universidade Federal da Bahia, resultado de convênio entre Brasil e França.

A curva obtida indicou a ocorrência de três oscilações positivas do nível do mar e duas negativas (Figura 4).

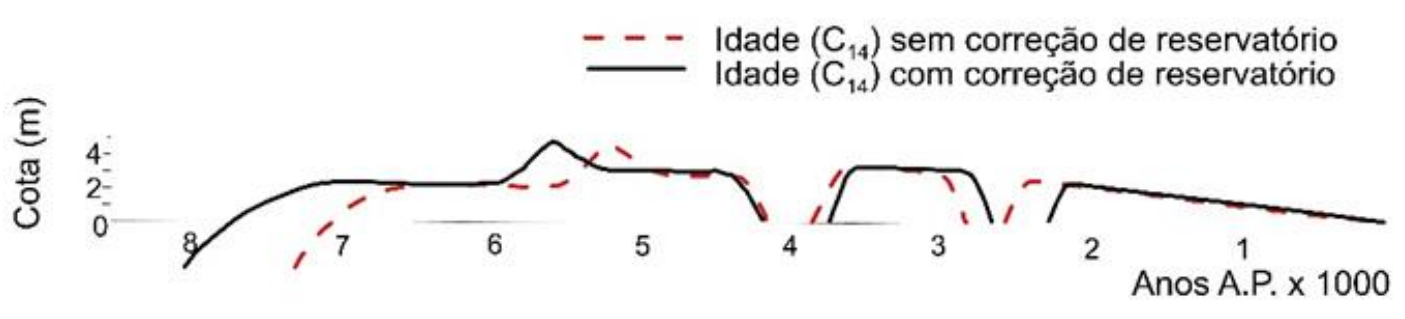

Figura 4. Superposição das curvas de variação do nível do mar nas proximidades de Salvador sem e com correção de reservatório, segundo Martin (2003).

A configuração da curva de variação do nível do mar induziu, no caso dos duplos cordões litorâneos, a associação da idade do cordão mais interiorizado e mais antigo, à idade do primeiro pulso transgressivo pós-glacial. Isto só foi revertido após os trabalhos de Ireland (1987) e Martin e Suguio (1989), tratando de amostras datadas dos depósitos entre as duas barreiras. Ou seja, se o cordão mais interiorizado fosse associado à idade de 6 mil anos A. P., não existiriam depósitos intracordões com idade superior, como no caso. Trabalho posterior de Angulo e Lessa (1997), a partir da reconstituição da curva de variação do nível do mar para Paranaguá (PR) e Cananéia (SP), não encontrou suporte para as oscilações encontradas nas reconstituições de Martin e colaboradores (MARTIN et al. 2003), mas sim a tendência de decréscimo gradual a partir do máximo transgressivo, o que vem gerando uma interessante discussão em artigos científicos, ainda não concluída (MARTIN et al 1998, e sua resposta em LESSA; ÂNGULO, 1998, e no Rio de Janeiro CASTRO et al. 2014, seguido de crítica de ANGULO et al. 2016). 


\section{Vulnerabilidade e resiliência em cenários de mudanças climáticas - a transição pa- ra a geografia costeira e marinha}

A obrigação legal de elaboração de Estudos de Impacto Ambiental prévios às intervenções potencialmente causadoras de danos ao meio ambiente, abriu oportunidades para um largo espectro de especialidades participarem desta tarefa, de caráter obrigatoriamente multi e interdisciplinar. A geomorfologia logo teve participação importante, pelo seu objeto de estudo. Diagnósticos passaram a ser feitos, sempre com participação de geomorfólogos nos capítulos específicos, juntamente com especialistas de outras áreas do conhecimento, inclusive de outras áreas da geografia, como nos estudos climáticos e socioeconômicos.

O primeiro desses diagnósticos, o Macrodiagnóstico da Zona Costeira na Escala da União (MMA, 1996), foi seguido de outro, atualizado e com inclusão do espaço marinho, denominado de Macrodiagnóstico da Zona Costeira e Marinha do Brasil (MMA 2016a). No tocante à vulnerabilidade da orla costeira a derrames de óleo, uma série de levantamentos regionalizados foi realizada, tanto para o Ministério do Meio Ambiente quanto para a empresa Petrobras, sempre com significativa descrição das características geomorfológicas e da morfodinâmica das praias. No que tange à gestão costeira, foi o Projeto Orla com seu conjunto de publicações (Subsídios para um Projeto de Gestão, 2004; Guia de Implementação, 2005; Implementação em Territórios com Urbanização Consolidada, 2006a; Manual de Gestão, 2006b; Fundamentos para Gestão Integrada, 2006c) o grande referencial metodológico. Já no domínio acadêmico, muitas iniciativas de aplicação e desenvolvimento metodológico podem ser registradas, em grande parte incentivadas pela busca da identificação de riscos associados às mudanças climáticas. Nesse sentido, a vulnerabilidade associada à erosão costeira levou à elaboração de um livro específico sobre o tema, com capítulos para cada estado federativo que possui costa marinha, desenvolvido pelos grupos de pesquisa associados ao Programa de Geologia e Geofísica Marinha (PGGM), e que contou com grande incentivo do Ministério do Meio Ambiente (MUEHE, 2006b), ao que se seguiu um segundo livro, em fase de submissão para publicação (MUEHE, 2018). Havia, portanto, preocupação do Governo e da comunidade científica quanto aos riscos relativos à erosão e à inundação costeira. A acelerada ocupação do litoral brasileiro nas proximidades dos grandes centros urbanos aumentou essa inquietação à medida que os riscos, devidos à elevação do nível do mar e ao aumento da intensidade e frequência de eventos extremos, foram sendo melhor percebidos. Assim, os trabaIhos que eram antes preferencialmente focados na descrição, classificação, e compreensão dos processos morfossedimentares, passaram a incorporar, de forma crescente, a avaliação da vulnerabilidade à erosão e inundação costeira, inclusive com desenvolvimento de técnicas e métodos novos (MAZZER et al. 2008; NGUYEN et al. 2016; SERAFIM; BONETTI, 2018; BONETTI et al. 2018 entre outros).

A participação em grupos multidisciplinares nos estudos de impacto ambiental, levou muitos geomorfólogos a um novo patamar de abordagem ao incorporar, nos estudos costeiros, variáveis socioeconômicas de forma integrada, passando do enfoque puramente geomorfológico para o geográfico, ou seja, para a Geografia Costeira (NICOLODI et al. 2009; NICOLODI; 
PETERMANN, 2010; VIANNA et al., 2012; LINS-DE-BARROS, 2013, 2018, por exemplo) e também para a Gestão Costeira Integrada (NICOLODI et al. 2009; VIANNA et al. 2012, entre outros).

Neste sentido, à medida que os estudos avançavam, o faziam também mar-a-fora, com a incorporação da antepraia (shoreface), zona de transição entre a praia subaérea e a plataforma continental interna (GRUBER; NICOLODI, 1998; GRUBER et al., 2006), enquanto nos primórdios do estudo de geomorfologia costeira as pesquisas se limitavam à porção emersa da costa. A caracterização do recobrimento sedimentar da plataforma continental, uma atividade típica da Geologia Marinha, foi também sendo incorporada aos estudos de Geomorfologia Costeira por parte de geógrafos-geomorfólogos, seja para fins de avaliação da direção de transporte sedimentar, como fonte de sedimento das praias (MUEHE; SUCHAROV, 1982), seja para a identificação de jazidas de areia para recuperação de praias (OLIVEIRA; MUEHE, 2013; MEDEIROS et al. 2014).

A familiarização com técnicas tais como batimetria e geofísica rasa como sonar de varredura, e sísmica de reflexão, fez com que mais uma vez as pesquisas se expandissem, incorporando desde porções rasas de estuários e lagoas costeiras, a regiões mais profundas do relevo submarino - principalmente da plataforma continental. Isto se deu sob diversas abordagens e representações como, por exemplo, através de modelo digital de terreno (BONETTI et al. 1998; MUEHE, 2006), pela associação entre a morfologia, a sedimentologia da plataforma continental, e a pesca artesanal (MUEHE; GARCEZ, 2005), pela associação entre a fisiografia do litoral e a pesca artesanal (GARCEZ, 2007), pela caracterização hidrográfica da plataforma continental (PINHEIRO et al. 2007), ou pela caracterização geomorfológica do relevo submarino (PEREIRA; BONETTI, 2018) e ainda para o mapeamento de paisagens marinhas (PEREIRA, 2016), apenas para citar alguns trabalhos oriundos da Geografia.

Os geógrafos, assim, incorporaram às suas competências o perfil técnico e metodológico muito específico associado aos estudos costeiros podendo-se, ainda, incluir as relações entre as zonas costeira e marinha com o turismo Telles $(2013,2015)$, ou a relação porto-cidade (MONIÉ, 2003, 2011; MONIÉ; VIDAL, 2006) que, a partir da integração da Geomorfologia Costeira, com a Geografia Costeira expandida para a zona oceânica, constituiu especialidade própria da Geografia, ou seja, da Geografia Marinha na concepção de Paffen (1964), Markov (1971), Psuty (PSUTY et al. 2006) e, mais precisamente, de Vallega (2002). Essa percepção, de uma Geografia Marinha cujos objetos de estudo são as relações entre os ambientes físicos e socioeconômicos do espaço costeiro e marinho, pode ser encontrada, também, em alguns trabalhos de geógrafos brasileiros como Gruber (GRUBER et al. 2003); Lins-de-Barros e Muehe, (2009) e Muehe, (2016).

Finalmente, falta dar um passo fundamental para a consolidação do campo de atividades dos geógrafos marinhos, que em complementação às regiões fisiográficas, biogeográficas, e oceanográficas, consiste no desenvolvimento de métodos e suas aplicações na identificação e na delimitação de regiões geográficas que, na concepção de Vallega (2002), se materializam em áreas submetidas a uma estrutura organizacional capaz de permitir a busca e obtenção de objetivos bem definidos em termos de ambiente, gestão e desenvolvimento econômico. Trata-se, portanto, de produto da interação do homem com o oceano e de ação política sobre o ambiente marinho. No Brasil, esta visão já encontra eco, por exemplo, nos trabalhos de Egler e Pires do Rio (2009) e Egler (EGLER et al. 2013), ao focar as áreas de exploração de petróleo. 


\section{Considerações finais}

Muitas mudanças ocorreram durante as últimas oito décadas, fazendo com que transacionássemos, quase imperceptivelmente, de uma realidade para outra, mais próxima à ficção, considerando o que era o mundo no início dessa caminhada. Nossos artigos eram, em geral, escritos à mão para depois serem datilografados, de preferência no formato Courier para, após várias e trabalhosas correções e inserções, serem enviados para publicação. Fotos tinham que ser reveladas e copiadas para inserção. Nos trabalhos de campo, o contato com amigos e familiares era, às vezes, impossível ou, em condições ideais, se podia utilizar um telefone público, que nos finais de semana formava longas filas. A localização de pontos de amostragem ao longo da praia e a localização de perfis, era muitas vezes feita com emprego do odômetro do carro, e no mar por meio de triangulação topográfica, emprego de odômetro a hélice, e utilizando radar no caso de embarcações maiores.

Fotos aéreas eram de cobertura limitada e geralmente não permitiam um georreferenciamento por falta de pontos de referência. Usava-se bússola, clinômetro, e equipamento topográfico básico como nível e teodolito. Nesse meio tempo, descobriu-se que a crosta terrestre, juntamente com parte do manto superior, se deslocava na forma de placas tectônicas e era responsável pela geração das unidades de relevo que compartimentalizam a superfície do nosso planeta. O Google Earth se tornou disponível e apresenta precisão suficiente para planejar campanhas de medição, acompanhar mudanças na configuração ou na ocupação da orla costeira, e na identificação de formas de fundo. Imagens de satélite, com precisão submétrica permitem realizar monitoramentos temporais, apenas inibidos pelo elevado custo das imagens. O telefone virou um minicomputador e falar é apenas uma das diferentes funções. Os computadores e notebooks pessoais realizam tarefas que só grandes computadores executavam na época. Surgiram equipamentos geofísicos com excelente resolução e precisão como batimetria de varredura, perfiladores de subsuperfície para áreas emersas e submersas, sistemas de posicionamento geodésico, sistemas de imageamento em terra e no mar por meio de LIDAR aerotransportado ou a partir de embarcações, ou mesmo a partir de drones ou veículos aéreos não tripulados (VANT's) de uso pessoal. Ou seja, um novo mundo, em que os trabalhos de campo tendem a ser realizados cada vez mais à distância e em gabinete defronte de um computador provido de inúmeros programas e sistemas de geoprocessamento e modelagem computacional.

Pari passu com esse incremento de tecnologia, cresceu a produção científica a ponto de não mais ser possível acompanhar a mesma, a não ser por tópicos muito específicos. Até certo ponto penso ser questionável a tendência de priorizar a produção em língua estrangeira atendendo a valorização dessa produção pelos órgãos de fomento, e pelos pares, visando a inserção do país na produção de pesquisa internacional. Será que isso aumenta a visibilidade desses trabaIhos? Afinal, para quem estamos escrevendo? Não me refiro às pesquisas de ponta nas diversas áreas de conhecimento. Para estas o fórum deve ser mesmo internacional. Mas, nos estudos básicos, de interesse internacional limitado, a aplicabilidade da maioria dos conhecimentos gerados seria principalmente destinada à comunidade não acadêmica nacional, aos técnicos dos diversos órgãos governamentais e de empresas, que necessitam dessas informações, e aos estudantes de graduação e pós-gradação. Então criamos duas barreiras para a difusão dos conhecimentos gerados. A barreira linguística, geralmente inglesa ou francesa, e a barreira da acessibilidade à pro- 
dução bibliográfica, tendo em vista que o acesso às revistas estrangeiras mais prestigiadas não é gratuito, ou é feito pelo Portal de Periódicos da CAPES, não disponível para a comunidade não acadêmica. Nesse cenário, a manutenção e valorização dos periódicos nacionais, nos seus diferentes graus de alcance, me parece uma estratégia desejável para que o produto dos conhecimentos gerados chegue com facilidade a quem os pode utilizar mais diretamente no desenvolvimento do país. 
Referências

AB'SÁBER, A. N. Revisão dos conhecimentos sobre o horizonte subsuperficial de cascalhos inhumados do Brasil Oriental. Boletim da Universidade do Paraná: Geografia Física, Curitiba, v. 2, p. 1-32, 1962.

Espaços ocupados pela expansão dos climas secos na América do Sul, por ocasião dos períodos glaciais quaternários. Paleoclimas, n. 3, p. 1-20, 1977.

ALBINO, J.; JIMENEZ, J. A.; OLIVEIRA, T. C. A. Planform and mobility in the Meaípe-Maimbá embayed beach on the South East coast of Brazil. Geomorphology, v. 253, p. 110-122, 2016. Disponível em: <https://ac.els-cdn.com/S0169555X15301586/1-s2.0S0169555X15301586-main.pdf?_tid=bb89255e-793e-4551-b1d8-

bc78b0582d46\&acdnat=1522497490_e2f01edcb9576fbd341a313317ecff96>. Acesso em: 31 mar. 2018.

ANGULO, R. J.; GIANNINI, P. C. F.; SOUZA, M. C.; LESSA, G. C. Holocene paleo-sea level changes along the coast of Rio de Janeiro, southern Brazil: Comment on Castro et al. (2014). Anais da Academia Brasileira de Ciências (Online), v. 88, n. 4, p. 1-7, 2016. Disponível em: <http://www.scielo.br/scielo.php?script=sci_arttext\&pid=S000137652016000602105\&lng=en\&nrm=iso>. Acesso em: 31 mar. 2018.

ANGULO, R. J.; LESSA, G. C. The Brazilian sea level curves: a critical review with emphasis on the curves from Paranaguá and Cananéia regions. Marine Geology, Amsterdam, v 140, p. 141-166, 1997. Disponível em: <https://ac.els-cdn.com/S0025322797000157/1-s2.0S0025322797000157-main.pdf?_tid=fd047c81-47c2-4d43-abdadd11909c5dfa\&acdnat=1522497828_ba55c455df2b9bf75ee63f7fd731954a>. Acesso em: 21 mar. 2018.

BARRETO, N. R.; SANTOS, J. R. U.; NASCIMENTO, T. M.; ALBINO, J. Alterações da morfologia em planta de uma praia de enseada após a instalação de estruturas rígidas: o caso de Itaipava, Espírito Santo. Revista Brasileira de Geomorfologia, v. 17, p. 331-346, 2016. Disponível em: <http://www.lsie.unb.br/rbg/index.php/rbg/article/view/838/538>. Acesso em: 30 mar. 2018.

BELLIGOTTI, F. M.; MUEHE, D. Levantamento do perfil da antepraia (shoreface) com uso de ecobatímetro portátil e caiaque. Revista da Gestão Costeira Integrada, v. 12, n. 2, p. 243248, 2012. Disponível em: <http://www.aprh.pt/rgci/rgci328.html>. Acesso em: 30 mar. 2018.

BIGARELLA, J. J.; SALAMUNI, R. Early Mesozoic wind patterns as suggested by dune bedding. Bulletin of the Geological Society of America, v. 72, p. 1089-1106, 1961.

BIGARELLA, J. J.; MOUSUINHO, M. R.; SILVA, J. X. Pediplanos, pedimentos e seus depósitos correlativos no Brasil. Boletim Paranaense de Geociências, v. 16/17, p. 117-151, 1965.

BIGARELLA, J. J.; ALESSI, A. H.; BEKKER, R. D.; DUARTE, G. M. Textural characteristics of the coastal dune, sand ridge and beach sediments. Boletim Paranaense de Geociências, v. 27, p. 15-80, 1969. 
BIGARELLA, J.J.; BECKER, RD.; DUARTE, G. N. Coastal dune structure from Paraná (Brazil). Marine Geology, v. 7, p. 5-55, 1969. Disponível em: $<$ https://books.google.com.br/books?id=ksNUAAAAYAAJ\&pg=PA410\&lpg=PA410\&dq=Coas tal+Dune+Structure+from+Paran\%C3\%A1+(Brazil).+Marine+Geology, +v.+7,+p.+5$55,+1969$ \&source=bl\&ots=S2iu8TYRag\&sig=FS7P0vllmHWpA4gY5aFmM1VilEE\&hl=en\&sa =X\&ved=0ahUKEwjJ9L3HgerZAhVEW5AKHdQdAHIQ6AEILjAB\#v=onepage\&q=Coastal\%20 Dune\%20Structure\%20from\%20Paran\%C3\%A1\%20(Brazil).\%20Marine\%20Geology\%2C\% 20v.\%207\%2C\%20p.\%205-55\%2C\%201969\&f=false>. Acesso em: 13 mar. 2018.

BIGARELLA, J. J. Palaeogeographische und Palaeoklimatishe aspekte des Kaenozolkums. Suedbrasilien. Zeitschrift für Geomorphologie, v. 3, p. 213-312, 1964.

Structural features at Lagoa Dune Field. In: MCKEE, Edwin D. (Ed.). A study of global sand seas. U. S. Geological Survey Professional Paper, 1052, p. 114-130, 1979.

Parabolic dune behavior under effective storm wind conditions. Revista Brasileira de Geomorfologia, v. 1 , p. 1-26, 2000. Disponível em: <http://www.Isie.unb.br/rbg/index.php/rbg/article/view/66/58>. Acesso em: 30 mar. 2018.

BITTENCOURT, A. S. P.; BOAS. G. S. V.; FARIAS, F. F. Variações direcionais nos parâmetros granulométricos: um indicador apropriado para o sentido da deriva litorânea. Revista Brasileira de Geociências, v. 22 n. 1, p.100-106, 1992. <Disponível em: http://ppegeo.igc.usp.br/index.php/rbg/article/view/11757/11294>. Acessado em: 2/03/2018.

BONETTI, J.; NUNES, M. G.; OLIVEIRA, M. S. C.; GRÉ, J. C. R. Caracterização do relevo submerso da Baía Norte - SC com base na aplicação de um Modelo Digital de Terreno. GEOSUL: Volume Especial: II Simpósio Nacional de Geomorfologia, v. 14, n. 27, p. 211217, 1998.

BONETTI, J.; RUDORFF, F. M.; CAMPOS, A. V.; SERAFIM, M. B. Geoindicator-based assessment of Santa Catarina (Brazil) sandy beaches susceptibility to erosion. Ocean \& Coastal Management, v. 156, p. 198-208, 2018. Disponível em: <https://ac.elscdn.com/S0964569117301631/1-s2.0-S0964569117301631-main.pdf?_tid=c5e67d1c-a09e4255-a9d6-2de997e805e1\&acdnat=1522451235_6b94d5359231adce751069168a84c7d1>. Acesso em: 23 mar. 2018.

CALLIARI, L. J.; KLEIN, A. H. F. Características morfodinâmicas e sedimentológicas das praias oceânicas entre Rio Grande e Chuí, RS. Pesquisas em Geociências, Instituto de Geociências da Universidade Federal do Rio Grande do Sul, v. 20, n. 1, p. 48-56, 1993.

CARVALHO, C. M. D. Fisiografia do Brasil. Rio de Janeiro: Editora Francisco Alves, 1927.

CARVALHO, A. M.; CLAUDINO-SALES, V. Instabilidade costeira em um litoral em espiral: o exemplo da praia da lagoinha, estado do Ceará. Revista Brasileira de Geomorfologia, v. 18, n. $1, \quad$ p. 51-64, 2017. Disponível em: <http://www.lsie.unb.br/rbg/index.php/rbg/article/view/973/582>. Acesso em: 30 mar. 2018

CARVALHO, A. M.; DOMINGUEZ, J. M. L.; MAIA, L. P. Interação entre deriva litorânea e potencial de formação de dunas na morfogênese costeira NW do Ceará. Mercator, Fortaleza, v. 3, n. 
5, p. 79-94, 2004. Disponível em: <http://www.mercator.ufc.br/mercator/issue/view/M5>. Acesso em: 30 mar. 2018.

CARVALHO, A. M.; ELLIS, J. T.; LEMOTHE, M.; MAIA, L. P. Using wind direction and shoreline morphology to model sand dune mobilization. Journal of Coastal Research, v. 32, n. 5, p. 1005-1015, $2016 . \quad$ Disponível em: <http://www.bioone.org.ez43.periodicos.capes.gov.br/doi/full/10.2112/JCOASTRES-D-1400258.1>. Acesso em: 30 mar. 2018.

CASTRO, J. W. A. Buring processes carried out by a mobile transversal dune field, Paracuru county, State of Ceará, Brazil. Environmental Geology, v. 49, n. 2, p. 214-218, 2005.

CASTRO, J. W. A.; RANGEL. Soterramento da estrada do Guriri na praia do Peró Cabo Frio - RJ, associado a dunas escalonares (climbing dunes). In: X Congresso da Ass. Brasileira do Quaternário - ABEQUA, Guarapari, 2005.

CASTRO, J. W. A.; SUGUIO, K.; SEOANE, J. C. S.; CUNHA, A. C.; DIAS, F. F. Sea-level fluctuations and coastal evolution in the state of Rio de Janeiro, southeastern Brazil. Anais da Academia Brasileira de Ciências (Impresso), v. 86, p. 671-683, 2014.

COE NETO, R. Algumas considerações sobre a origem do sistema lagunar de Araruama. In: LACERDA, L. D.; ARAÚJO, D. S. D.;CERQUEIRA, R.; TURCQ, B. Restingas: origem, estruturas e processos. In: Simpósio sobre Restingas Brasileiras, 1984. Anais... Niterói: CEUFF Universidade Federal Fluminense, p.61-63, 1984.

CAILLEUX, A. La ligne de cailloutis a la base des sols jaunes. Zeitschrift für Geomorphologie, v. 1, p. 312-, 1957.

DEAN, R. G. Equilibrium beach profiles: U. S. Atlantic and Gulf Coast. Ocean Engineering report, n. 12, University of Delaware, 1977, 45 p.

DILLENBURG, S. R.; HESP, P. A. Coastal Barriers. In: S.R DILLENBURG; P.A. HESP (Org.). Geology and Geomorphology of Holocene Coastal Barriers of Brazil. 1 ed. Berlin/Heidelberg: Springer, v. 107, p. 1-15. 2009.

DINIZ, M. T. M; OLIVEIRA, G. P. Proposta de compartimentação em mesoescala para o litoral do nordeste brasileiro. Revista Brasileira de Geomorfologia (Online), São Paulo, v. 17, n. 3, p. 565-590, jul./set. 2016.2 Disponível em: <http://www.lsie.unb.br/rbg/index.php/rbg/article/view/844>. Acesso em: 30 mar. 2018.

DINIZ, M. T. M.; VASCONCELOS, F. P.; OLIVEIRA; G. P.; MEDEIROS, D. B. S. Geografia costeira da Nordeste. Curitiba: Editora VRV, 2016. 133p.

DOMINGUEZ, J. M. L. Deltas dominados por ondas: crítica às ideias atuais com referência particular ao modelo de Coleman \& Wright. Revista Brasileira de Geociências, São Paulo, v. 20, n. 1-4, p. 352-361, 1990. Disponível em: <http://ppegeo.igc.usp.br/index.php/rbg/article/view/11866>. Acesso em: 31 mar. 2018.

. The coastal zone of Brazil: an overview. Journal of Coastal Research, SI 39, p. 16-20, 2004. 
DOMINGUEZ, J. M. L. As costas do Brasil - proposição de uma nova tipologia. XI Congresso da ABEQUA, Belém, 4-11 de novembro de 2007, Anais... 2007.

The coastal zone of Brazil. In: DILLENBURG, S. R.; HESP, P. A. (Eds.), Geology and geomorphology of Holocene coastal barriers of Brazil, Springer, p.16-51, 2009.

DOMINGUEZ J. M. L.; BITTENCOURT, A. C. S. P. Utilização de padrões de sedimentação costeira como indicadores paleoclimáticos naturais (proxies). Revista Brasileira de Geociências, v. 24, n. $1, \quad$ p. 3-12, 1994. Disponível em: <http://ppegeo.igc.usp.br/index.php/rbg/article/view/11545/11003>. Acesso em: 1 mar. 2018.

DOMINGUEZ, J. M. L.; BITTENCOURT, A. C. S. P.; MARTIN, L. Esquema evolutivo da sedimentação quaternária das feições deltaicas dos rios São Francisco (SE/AL), Jequitinhonha (BA), Doce (ES) e Paraíba do Sul (RJ). Revista Brasileira de Geociências, v. 11, n. 4, p. 227237, 1981.

DOMINGUEZ, J. M. L.; MARTIN, L.; BITTENCOURT, A. C. S. P.; FERREIRA, Y. A.; FLEXOR, J. M. Sobre a validade da utilização do termo Delta para designar as planícies costeiras associadas à desembocaduras dos grandes rios da costa brasileira. In: XXXII Congresso Brasileiro de Geologia, 1982, Salvador. Boletim de Resumos e Breves Comunicações. Salvador: Sociedade Brasileira de Geologia, v. 2, p. 92-92, 1982.

DOURADO, F. A.; SILVA. A. S. Monitoramento do avanço da frente de dunas na região do Peró, Cabo Frio, Rio de Janeiro. XII Simpósio Brasileiro de Sensoriamento Remoto, Goiânia. Anais... INPE, p. 2957-2964, 2005.

EMERY, K. O. A simple method of measuring beach profiles. Limnological Ocenography, v. 6, p. 90-93, 1961.

EGLER, C. A. G.; GUSMÃO, P. P.; SANTOS, B. B. M. Governança e desenvolvimento territorial: uma visão a partir da zona costeira do sudeste brasileiro. In: Encontros Nacionais da ANPUR, 2013. Anais... v. 15, p. 1-18, 2013.

EGLER, C. A. G.; PIRES DO RIO, G. A. Territórios do petróleo no Brasil: redes globais e governança local. In: GUIBERT, M. (Ed.). Le bassin du Rio de la Plata : intégration régionale et développement local. Toulouse: Presses Universitaires du Mirail, 2009. p.239-256.

FARIA, A. P. Dinâmica geomorfológica da costa rochosas do Estado do Rio de Janeiro. Revista Brasileira de Geomorfologia (online), v. 19 n. 1, 2018. Disponível em: <http://www.lsie.unb.br/rbg/index.php/rbg/article/view/718>. Acesso em: 30 mar. 2018.

FERNANDEZ, G. B.; PEREIRA, T. G.; ROCHA, T. P.; MALUF, V.; MOULTON, M.; OLIVEIRA FILHO, S. R. Classificação morfológica das dunas costeiras entre o Cabo Frio e o Cabo Búzios, litoral do estado do Rio de Janeiro. Revista Brasileira de Geomorfologia, v. 18, n. 3, p. 595-622, 2017.2 Disponível em: <http://www.lsie.unb.br/rbg/index.php/rbg/article/view/862>. Acessado em: 30 mar. 2018.

FOLK, R. L. Petrology of sedimentary rocks. Austin (Texas): Memphill Publishing Company, 1984. 184 p. 
FOLK, R. L.; WARD, W. C. Brazos river bar: a study in the significance of grain size parameters. Journal of Sedimentary Petrology, v. 27, n. 1, p. 3-26, 1957.

GABAGLIA, F. A. R. As fronteiras do Brasil. Rio de Janeiro: Jornal do Comércio, 1916. 78p.

GARCEZ, D. S. Caracterização da pesca artesanal autônoma em distintos compartimentos fisiográficos e suas áreas de influência, no estado do Rio de Janeiro. Tese (Doutorado em Geografia) - Programa de Pós-Graduação em Geografia, Universidade Federal do Rio de Janeiro,. 2007.

GONCAlVES, R. A.; LeBugeuR, L. G. O.; CASTRO, J. W. A.; PEDROTO, A. E. S. Classificações das feições eólicas dos Lençóis Maranhenses - Estado do Maranhão - Brasil. Mercator, Fortaleza, v. 2, n. 3, p. 99-112, 2003. Disponível em: <http://www.mercator.ufc.br/mercator/article/view/169>. Acesso em: 30 mar. 2018.

GOURLAY, M. R, Beach and dune erosion tests. Delft Hydraulics Laboratory, Report n. M935/M936, 1968.

GRUBER, N. L. S.; BARBOZA, E.; NICOLODI, J. L. Geografia dos sistemas costeiros e oceanográficos: subsídios para Gestão Integrada da Zona Costeira. Porto Alegre: Gravel, COMAR, $\quad$ v. $1, \quad$ p. 81-89, 2003. Disponível em: <http://www.ufrgs.br/gravel/portugues/publica.htm>. Acesso em: 30 mar. 2018.

GRUBER, N. L. S. ; NICOLODI, J. L. Limites Externos da antepraia com base na morfologia e sedimentologia em Tramandaí - RS. Geosul, Volume Especial: II Simpósio Nacional de Geomorfologia, Florianópolis, v. 14, n. 27, p.235-238, 1998.

GRUBER, N.L.S.; TOLDO JR., E.E.; NICOLODI, J.L.; AYUPZOUAIN, R.N. A shoreface morphodynamic zonation and the equilibrium profile variability on the Northern coastline of Rio Grande do Sul, Brazil. Journal of Coastal Research, v.39, p. 504-508, 2006.

HESP, P. A.; DILLENBURG, S. R.; BARBOZA, E. G.; TOMAZELLI, L. J.; AYUP-ZOUAIN, R. N.; ESTEVES, L. S. ; GRUBER, N. L. S.; TOLDO Jr., E. E.; TABAJARA, L. L. C. A.; CLEROT, L. C. P. Beach ridges, foredunes or transgressive dune fields? definitions and an examination of the Torres to Tramandai barrier system, Southern Brazil. Anais da Academia Brasileira de Ciências, Rio de Janeiro - RJ, v. 77, n. 3, p. 4 93-508, 2005. Disponível em: $<$ http://www.scielo.br/scielo.php?script=sci_arttext\&pid=S0001-

$37652005000300010 \&$ Ing=en\&nrm=iso >. Acesso em: 31 mar. 2018.

HOYT, J. H. Barrier island formation. Geological Society of American Bulletin, v. 78, p. 11251135, 1967.

HSU, J. R. C.; SILVESTER, R.; XIA, Y. M. New characteristics of equilibrium shaped bays. Proceedings 8th International Conference on Coastal Engineering, ASCE, p. 140-144, 1987.

IRELAND, S. The Holocene sedimentary history of the coastal lagoons of Rio de Janeiro state, Brazil. In: TOLEY, M. J.; SHENNAN, I. (ed.). Sea level changes. The Institute of British Geographers Special Publications Series 20, 1987. p.25-66. 
JIMENEZ, J.; MAIA, L. P.; RAVENTOS, J. S.; MORAIS, J. O. Dune migration along the Ceará coast, Northeastern Brazil. Sedimentology, v. 46, p. 689-701, 1999.

KLEIN, A. H. F.; BENEDET FILHO, L.; HSU, J. R. C. Stability of headland bay beaches in Santa Catarina: A case study. Journal of Coastal Research, Itajaí, SC, v. SI 35, p.151-166, 2003.

KLEIN, A. H. F.; MAIA, L. P. First Brazilian Symposium on Dunes Systems and International Symposium on Coastal Dunes: A Report of Meeting. Journal of Coastal Research, v. 24, n. 6, p.1355-1356, 2008. Disponível em: <http://www.bioone.org.ez43.periodicos.capes.gov.br/doi/full/10.2112/08A-0010.1>. Acesso em: 30 mar. 2018.

KOWSMANN, R. O. Variações de curto e longo prazo de um perfil na praia de Copacabana, Rio de Janeiro. Publicação do Instituto de Pesquisas da Marinha, v. 39, n. 9. p. 1-15, 1870.

KRUMBEIN, W. Size frequency distributions of sediments. Journal of Sedimentary Petrology, v. 4, p. 66-77, 1934.

LAMEGO, A. R. Restingas na costa do Brasil, Rio de Janeiro. Boletim da Divisão de Geologia e Mineralogia, n. 96, 66p. 1940.

. Ciclo evolutivo das lagunas fluminenses. Departamento Nacional da Produção Mineral, Rio de Janeiro, Boletim n. 118, 1945. 45p.

LESSA, G. C.; ANGULO, R.J. Oscillations or not oscillations, that is the question - Reply. Marine Geology, Amsterdam, v. 150, p. 189-196, 1998. Disponível em: <https://ac.elscdn.com/S0025322798000450/1-s2.0-S0025322798000450-main.pdf?_tid=3e0eb46a-b1af4080-83fc-f0f6e630411b\&acdnat=1522502414_2d0c8a2cde72beb1359bd15c0c447ceb>. Acesso em: 31 mar. 2018.

LINS-DE-BARROS, F. M. Integrated coastal vulnerability assessment: a methodology for coastal cities management integrating socioeconomic, physical and environmental dimensions - case study of Região dos Lagos, Rio de Janeiro, Brazil. Ocean \& Coastal Management, v. 149, p. 1-11, 2017. Disponível em: <https://ac.els-cdn.com/S0964569117300145/1-s2.0S0964569117300145-main.pdf?_tid=1b9ec560-4bf6-4623-9366-

ba9ae6be9c6c\&acdnat=1521852263_8bf979221c647b282e94062ece22a52f $>$. Acesso em 23 mar. 2018.

LINS-DE-BARROS, F. M.; MUEHE, D. Tradição da Geografia nos Estudos Costeiros. Mercator (UFC), v. 8, n. 16, p. 77-102, 2009. Disponível em: <http://www.mercator.ufc.br/mercator/article/view/214>. Acesso em: 30 mar. 2018.

.. The smartline approach to coastal vulnerability and social risk assessment applied to a segment of the east coast of Rio de Janeiro State, Brazil. Journal of Coastal Conservation, v. 17, p. 211-223, 2013.

MACHADO, G. M. V.; JABOR, P. M.; COELHO, A. L. N.; ALBINO, J. Geohistorical evolution and the new geological map of the city of Vitoria, ES, Brazil. Ocean \& Coastal Management, $v$. 151, p 45-52, 2018. Disponível em: <https://ac.els-cdn.com/S0964569117301606/1-s2.0S0964569117301606-main.pdf?_tid=6ccdf9ff-b84f-45c4-8029- 
07e1a21f5686\&acdnat=1522452098_438829edeea4a024158f87c1589d017b>. Acesso em: 1 abr. 2018.

MAIA, L. P.; FREIRE, G. S. S.; LACERDA, L. D. Accelerated dune migration and eolian transport during El Niño events along the NE Brazilian Coast. Journal of Coastal Research, v. 21, n. 6, p. 1121-1126, 2005. Disponível em: <http://www.bioone.org.ez43.periodicos.capes.gov.br/doi/pdf/10.2112/03-702A.1>. Acesso em: 30 mar. 2018.

MARKOV, K. K. Marine geography. Soviet Geography, v. 12, n. 6, p. 346-350, jun., 1971.

MARTIN, L. Holocene sea-level history along Eastern-Southeastern Brazil. Anuário do Instituto de Geociências - UFRJ, Rio de Janeiro, v. 26, p. 13-24, 2003. Disponível em: <http://www.anuario.igeo.ufrj.br/anuario_2003/anuario_igeo_2003_louis.pdf>. Acesso em: 31 mar. 2018.

MARTIN, L.; ABSY, M. L.; FLEXOR, J. M.; TURCQ, B.; MOURGUIART, P.; SIFEDDINE, A.; FOURNIER, M. Southern Oscillation signal in the palaeoclimatic field evidence of South America during the last 7000 years. Quaternary Research, New York, v. 39, p. 338-346, 1993.

MARTIN, L.; BITTENCOURT, A. C. S. P.; DOMINGUEZ, J. M. L.; FleXOR, J. M.; SUGUIO, K. Oscillations or not oscillations, that is the question: Comment on Angulo, R. J. and Lessa, G. C. "The Brazilian sea-level curves: a critical review with emphasis on the curves from the Paranaguá and Cananéia regions" [Mar. Geol. 140, 141-166]. Marine Geology, New York, v. 150, p. 179-187, 1998.

MARTIN, L.; DOMINGUEZ, J. M. L.; BITTENCOURT, A. C. S. P.; Fluctuating Holocene Sea Levels in Eastern and Southeastern Brazil: evidence from multiple fossil and geometric indicators. Journal of Coastal Research, West Palm Beach (Florida), v. 19, n. 1, p. 101-124, 2003.

MARTIN, L.; FLEXOR, J. M. Porque a planície costeira do Rio Paraíba do Sul não pode ser denominada de "clássico delta denominado por ondas". In: Simpósio de Geologia Regional RJES, 1, Rio de Janeiro, Sociedade Brasileira de Geologia. Anais... p. 70-84, 1987.

MARTIN, L.; FLEXOR, J.M.; BITTENCOURT, A. C. S. P.; DOMINGUES, J. M. L. Registro do bloqueio da circulação atmosférica meridiana na geometria dos cordões litorâneos da costa brasileira. XXXIII Congresso Brasileiro de Geologia. Anais... p. 133-144, 1984.

MARTIN, L.; FLEXOR J. M.; VILAS BOAS, G. S.; BITTENCOURT, A. C. S. P.; GUIMARÃES, M. M. M. Courbe de variation du niveau relatif de la mer au cours des 7.000 dernières années sur un secteur homogène du littoral brésilien (nord de Salvador). In: International Symposium On Coastal Evolution in The Quaternary, São Paulo. Proceedings..., p. 264-274, 1979.

Curve of variation of the sea-level during the last 7000 years in a homogeneous section of the Brazilian coast ( $\mathrm{N}$ of Salvador). In: International Symposium on Coastal Evolution in the Quaternary. Special Publication, 3, São Paulo, INQUA, SBG. Anais... Resumo, p. 39-40, 1978.

MARTIN, L. M.; SUGUIO, K. Excursion route along the Brazilian coast between Santos (state of São Paulo) and Campos (state of Rio de Janeiro). International Symposium on Global 
Changes in South America during the Quaternary - Special Publication n. 2. São Paulo, 1989. $136 \mathrm{p}$.

MARTINS, L. Aspectos texturais e deposicionais dos sedimentos praiais e eólicos da planície costeira do Rio Grande do Sul. Escola de Geologia (UFGS): Publicação Especial, Porto Alegre, v. 13, p. 1-102, 1967.

MAZZER, A. M.; DILLENBURG, S. R.; SOUZA, C. R. G. Proposta de método para análise de vulnerabilidade à erosão costeira no Sudeste da Ilha de Santa Catarina, Brasil. Revista Brasileira de Geociências, v. 38, n. 2, p. 278-294, 2008. Disponível em: <http://ppegeo.igc.usp.br/index.php/rbg/article/view/7584/7011>. Acesso em: 31 mar. 2018.

MEDEIROS, N.; DIAS, M. S.; AYRES NETO, A.; MUEHE, D. Mapeamento acústico de areias submersas para recuperação de praias do Rio de Janeiro, Brasil. Revista da Gestão Costeira Integrada, v. 14, n. 1, p. 149-158, 2014. Disponível em: <http://www.aprh.pt/rgci/rgci429.html>. Acesso em: 31 mar. 2018.

MEIRELES, A. J. A. Geodinâmica dos campos de dunas móveis de Jericoacoara/CE-Br. Mercator, v. 10, n. 22, p. 169-190, 2011. Disponível em: <http://www.mercator.ufc.br/mercator/article/view/663>. Acesso em: 7 mai. 2018.

MESQUITA, A. F.; SILVA FILHO, W. F.; DUARTE, C. R.; BEZERRA, F. H. R.; VASCONCELOS, D. L.; SOUSA, J. P. Faciologia e evolução dos depósitos eólicos costeiros do oeste do Ceará (Brasil) no Holoceno tardio. Revista Brasileira de Geomorfologia, v. 17, n. 4, p. 783799, 2016. Disponível em: <http://www.lsie.unb.br/rbg/index.php/rbg/article/view/832>. Acesso em: 30 mar. 2018.

MMA - MINISTÉRIO DO MEIO AMBIENTE. Macrodiagnóstico da zona costeira do Brasil na escala da União. Brasília: MMA, UFRJ, LAGET, 1996. 280 p.

. Macrodiagnóstico da Zona Costeira e Marinha do Brasil. Brasília, 2008. 242 p. Disponível

em:

$<$ http://www.laget.eco.br/index.php?option=com_content\&view=article\&id=62:macrodiagnosti co\&catid=43: mapas-e-cartas\&ltemid=5>. Acesso em: 24 mar. 2016.

MONIÉ, F. Petróleo, industrialização e organização do espaço regional. In: PIQUET, R. (org.). Petróleo, royalties e região. Rio de Janeiro: Garamond, v.1, 2003. p. 257-285

- Globalização, modernização do sistema portuário e relações cidade/porto no Brasil. In: SILVEIRA, Márcio Rogério (org.): Geografia dos transportes, circulação e logística no Brasil. São Paulo: Outras Expressões, Col. Geografia em movimento, 2011. p.299-330. Disponível

em: <http://www.academia.edu/4828521/GLOBALIZA\%C3\%87\%C3\%830_MODERNIZA\%C3\%8 7\%C3\%830_DO_SISTEMA_PORTU\%C3\%81RIO_E_RELA\%C3\%87\%C3\%95ES_CIDADE _PORTO_NO_BRASIL>. Acesso: 31 mar. 2018.

MONIÉ, F.; VIDAL S. M. S. C. Cidades, portos e cidades portuárias na era da integração produtiva. Revista de Administração Pública, Rio de Janeiro, v. 40, n. 6, p. 975-995, 2006.

MORENO, L. J.; KRAUS, N. C. Equilibrium shape of headland-bay beaches for engineering design. Proc. Coastal Sediments'99, ASCE, v. 1, p.860-875, 1999. 
MOULTON, M.; OLIVEIRA FILHO, S. R.; ROCHA, T. B.; FERNANDEZ, G. B. Foredunes of Rio de Janeiro coast: genesis, structure and morphology. Journal of Coastal Research, SI 65, v. 2. 1 p. 1319-1324, 2013. Disponível em: <http://www.bioone.org.ez43.periodicos.capes.gov.br/doi/pdf/10.2112/SI65-223.1>. Acesso em: 30 mar. 2018.

MUEHE, D. Análise ambiental no sistema costeiro sul-oriental do estado do Rio de Janeiro. Dissertação (Mestrado em Geografia). Programa de Pós-graduação em Geografia, Universidade Federal do Rio de Janeiro, 1975.

. Sedimentology and topography of a high energy coastal environment between Rio and Cabo Frio. Anais da Academia Brasileira de Ciências, Rio de Janeiro, v. 51, n. 3, p. 473481, 1979.

. Consequências hidroclimáticas das glaciações quaternárias na evolução do relevo costeiro a leste da Baía de Guanabara. Revista Brasileira de Geociências, São Paulo, v. 19, n. 3, $\quad$ p. 387-392, $1983 . \quad$ Disponível em: $<$ https://www.researchgate.net/publication/258093015_Consequencias_higroclimaticas_das_ glacia-

coes_quaternarias_na_evolucao_do_relevo_costeiro_a_leste_da_Baia_de_Guanabara>. Acesso em: 2 abr. 2018.

. Evidências de recuo dos cordões litorâneos em direção ao continente no litoral do Rio de Janeiro. In: LACERDA, L. D.; ARAÚJO, D. S. D.; CERQUEIRA, R.; TURCQ, B. Restingas: origem, estruturas e processos. In: Simpósio sobre Restingas Brasileiras, Niterói, CEUFF Universidade Federal Fluminense, Anais... p. 75-80, 1984.

. Estado Morfodinâmico praial no instante da observação: uma alternativa de identificação. Revista Brasileira de Oceanografia, Instituto Oceanográfico USP, v. 46, n. 2, p. 157-169, 1998. Disponível em: <https://www.revistas.usp.br/rbo/article/view/6833/8302>. Acesso em: 31 mar. 2018.

. O litoral brasileiro e sua compartimentação. In: CUNHA, Sandra Baptista da; GUERRA, Antonio José Teixeira. (Org.). Geomorfologia do Brasil. Rio de Janeiro: Bertrand Brasil S.A., 1998. p. 273-349.

Beach morphodynamic research in Brazil: evolution and applicability. Journal of Coastal Research, Itajaí (SC), SI 35, p. 37-42, 2003.

- Método de levantamento topo-batimétrico do sistema praia-antepraia. Revista Brasileira de Geomorfologia, v. 5, n. 1, p. 95-100, 2004. Disponível em: <http://www.lsie.unb.br/rbg/index.php/rbg/article/view/285>. Acesso em: 30 mar. 2018.

Aspectos gerais da erosão costeira no Brasil. Mercator, v. 4, n. 7 p. 97-110, 2005. Disponível em: <http://www.mercator.ufc.br/mercator/article/view/113>. Acesso em: 30 mar. 2018.

. Erosion in the Brazilian coastal zone: an overview. Journal of Coastal Research, SI 39, p. 43-48, 2006a. 
MUEHE, D. Erosão e Progradação do Litoral Brasileiro. Brasília: Ministério do Meio Ambiente, 2006b. 475p. Disponível em: <http://www.mma.gov.br/publicacoes/gestaoterritorial/category/80-gestao-costeira-g-erosao-e-progradacao>. Acesso em: 22 mar. 2018.

. Gênese da morfologia do fundo da Lagoa de Araruama e cordões litorâneos associados. In: VI Simpósio Nacional de Geomorfologia / Regional Conference on Geomorphology, União da Geomorfologia Brasileira (UGB), Goiania, v.II. Anais... 2006c. Disponível em: $<$ https://www.researchgate.net/publication/259930798_Genese_da_morfologia_do_fundo_da _lagoa_de_Araruama_e_cordoes_litoraneos_associados>. Acesso em: 1 abr. 2018.

A zona costeira do Brasil e sua vulnerabilidade face à ocupação e às mudanças climáticas. In: MENDONÇA, F.; LÖWEN-SAHR, C. L.;SILVA, M. (orgs.). Espaço e tempo: complexidade e desafios do pensar geográfico. Curitiba: Ademadan, 2009. p. 425-439.

Brazilian coastal vulnerability to climate change. Pan-American Journal of Aquatic Sciences, $\quad$ v. $5, \quad$ n. 2 p. 173-183, 2010. Disponível em: <http://www.panamjas.org/artigos.php?id_publi=183>. Acesso em: 3 mar. 2018.

. Geografia Marinha - A retomada do espaço perdido. Revista da ANPEGE, v. 12, p. 185210, 2016.

- (submetido). Panorama da erosão costeira no Brasil. Revista Brasileira de Geofísica, Programa de Geologia Marinha (PGGM), 2018.

MUEHE, D.; BELLIGOTTI, F. M.; LINS-DE-BARROS, F. M.; OLIVEIRA. J. F.; MAIA, L. F. P. Potential vulnerability to climate change of the beach-dune system of the Peró coastal plain Cabo Frio, Rio de Janeiro state, Brazil. Pan-American Journal of Aquatic Sciences, v. 5, n. 2, p. 267-276, 2010. Disponível em: <http://www.panamjas.org/artigos.php?id_publi=183>. Acesso em: 3 mar. 2018.

MUEHE, D.; DOBEREINER, C. Dinâmica do fundo marinho ao longo do pier de Ipanema. Academia Brasileira de Ciências, Anais, v. 33, n. 2, p. 103-136, 1971.

MUEHE, D.; GARCEZ, D. S. A plataforma continental brasileira e sua relação com a zona costeira e a pesca. Mercator, v. 4, n. 8, p. 69-88, 2005. Disponível em: <http://www.mercator.ufc.br/mercator/article/view/100>. Acesso em: 30 mar. 2018.

MUEHE, D.; NEVES, C. F. The implication of sea level rise on the Brazilian coast: a preliminary assessment. Journal of Coastal Research, SI 14, p. 54-78, 1995.

MUEHE, D.; SUCHAROV, E. Considerações sobre o transporte de sedimentos na plataforma continental nas proximidades das Ilhas Maricas - Rio de Janeiro. Revista Brasileira de Geociências, v. 11, n. 4, p. 238-246, 1982.

NGUYEN, T. T. X.; BONETTI, J.; ROGERS, K.; WOODROFFE, C. D. Indicator-based assessment of climate-change impacts on coasts: A review of concepts, methodological approaches and vulnerability indices. Ocean \& Coastal Management, v. 123, p. 18-43, 2016. Disponível em: $<$ https://ac.els-cdn.com/S0964569115300715/1-s2.0-S0964569115300715-

main.pdf?_tid=f9c45abb-e336-4498-9cbbd6d59b5b728a\&acdnat=1522451561_a6493e658c59d3046478962587b8649c>. Acesso em 30 mar. 2018. 
NICOLODI, J. L.; PETERMANN, R. M. Potential vulnerability of the Brazilian coastal zone in its environmental, social, and technological aspects. Pan-American Journal of Aquatic Sciences, v. $5, \quad$ n. 2, p. 184-204, 2010. Disponível em: <http://www.panamjas.org/pdf_artigos/PANAMJAS_5(2)_184-204.pdf>. Acesso em: 31 mar. 2018.

NICOLODI, J. L.; ZAMBONI, A.; BARROSO, G. F. Gestão integrada de bacias hidrográficas e zonas costeiras no Brasil: Implicações para a Região Hidrográfica Amazônica. Revista da Gestão Costeira Integrada, v. 9, n. 2, p. 9-32, 2009. Disponível em: <http://www.aprh.pt/rgci/rgci115.html>. Acesso em: 30 mar. 2018.

OLIVEIRA, J. F.; MUEHE, D. Identificação de áreas de sedimentos compatíveis na plataforma continental interna para recuperação de praias entre as cidades de Niterói e Macaé - Rio de Janeiro, Brasil. Revista da Gestão Costeira Integrada, v. 13, n. 1, p. 89-99, 2013. Disponível em: <http://www.aprh.pt/rgci/pdf/rgci-362_Oliveira.pdf>. Acesso em: 31 mar. 2018.

OLIVEIRA, C. K. R.; SALGADO, A. A. R. Geomorfologia brasileira: panorama geral da produção nacional de alto impacto no quinquênio entre 2006-2010. Revista Brasileira de Geomorfologia, v. 14, n. 1, p. 117-123, 2013. Disponível em: <http://www.lsie.unb.br/rbg/index.php/rbg/article/view/421>. Acesso em: 30 mar. 2018.

OTTMAN, J.; NÓBREGA, R.; COUTINHO, P. N.; OLIVIERA, S. P. B, Estudo topográfico e sedimentológico de um perfil na praia da Piedade - Recife - Pernambuco. Trabalhos do Instituto de Biologia Marinha, Universidade de Recife, v. 1, p. 19-37, 1959.

PAFFEN, K. Maritime Geographie. Die Stellung der Geographie des Meeres und ihre Aufgaben im Rahmen der Meeresforschung. Erdkunde, v. 18, p.40-62, 1964. Disponível em: $<$ https://www.erdkunde.uni-bonn.de/archive/1964/maritime-geographie.-die-stellung-dergeographie-des-meeres-und-ihre-aufgaben-im-rahmen-dermeeresforschung/at_download/attachment>. Acesso em: 1 abr. 2018.

PALMA, J. J. C. Geomorfologia da plataforma continental norte brasileira. In: Geomorfologia da margem continental brasileira e das áreas oceânicas adjacentes. Série Projeto REMAC, n.7. Rio de Janeiro: PETROBRÁS; CENPES; DINTEP, 1979. p. 25-51.

PARTELI, E. J. R.; HERRMANN, H. J.; MAIA, L. P.; MONTEIRO, L. H. U. Profile measurement and simulation of a transverse dune field in the Lençóis Maranhenses. Geomorphology, v. 81, n. 1-2, p. 29-42, 2006. Disponível em: <https://ac.els-cdn.com/S0169555X06001073/1s2.0-S0169555X06001073-main.pdf?_tid=aa2616fd-5611-4503-a419-

30886869fd36\&acdnat=1522532023_a268061c92b31d16f324dd3bc8c99f06>. Acesso em 31 mar. 2018.

PEREIRA, M. L. M. Classificação da paisagem marinha de unidades de conservação marinho-costeiras com auxílio de sistema de informações geográficas: os casos da Reserva Biologica Marinha do Arvoredo, Parque Nacional Marinho de Abrolhos e Parque Nacional Marinho De Fernando de Noronha. Tese (Doutorado em Geografia) - Programa de Pósgraduação em Geografia, Universidade Federal de Santa Catarina, 2016.

PEREIRA, M. L. M.; BONETTI, J. Caracterização geomorfológica do relevo submarino de áreas marinhas protegidas brasileiras com base em técnicas de análise espacial. Revista Brasi- 
leira de Geomorfologia, v. 19, n. 1, p. 127-147, 2018. Disponível em: <http://www.lsie.unb.br/rbg/index.php/rbg/article/view/1008>. Acesso em: 30 mar. 2018.

PINHEIRO, L. S.; SILVA, A. C.; ARAUJO, M. Caracterização hidrográfica da plataforma continental do Maranhão a partir de dados oceanográficos medidos, remotos e modelados. Revista Brasileira de Geofísica (Impresso), v. 25, p. 281-294, 2007.

PROJETO ORLA. Subsídios para um Projeto de Gestão. Brasília: MMA; MPO, 2004. 104 p. Disponível em: <http://www.mma.gov.br/estruturas/orla/_arquivos/11_04122008110506.pdf>. Acesso em: 26 mar. 2018.

. Guia de Implementação. Brasília: Ministério do Meio Ambiente; Ministério do Planejamento, Orçamento e Gestão, 2005. 36 p. Disponível em: <http://www.mma.gov.br/estruturas/orla/_publicacao/11_publicacao22012009042111.pdf>. Acesso em: 20 mar. 2018. 36 p.

Implementação em Territórios com Urbanização Consolidada. Brasília: Ministério do Meio Ambiente; Ministério do Planejamento, Orçamento e Gestão 2006a. 78 p. Disponível em:

<http://www.mma.gov.br/estruturas/orla/_publicacao/11_publicacao22012009042111.pdf>. Acesso em: 20 mar. 2018.

Manual de Gestão. Brasília: Ministério do Meio Ambiente; Ministério do Planejamento, Orçamento e Gestão, 2006b. 88 p. Disponível em: <http://www.mma.gov.br/estruturas/orla/_arquivos/11_04122008110636.pdf >. Acesso em: 20 mar. 2018.

Fundamentos para Gestão Integrada. Brasília: Ministério do Meio Ambiente; Ministério do Planejamento, Orçamento e Gestão, 2006c. 74p. Disponível em: http://www.mma.gov.br/estruturas/orla/_arquivos/11_04122008111238.pdf. Acesso em: 26 Mar. 2018. 74 p.

PSUTY, N. P.; STEINBERG, P. E.; WRIGTH, D. J. Coastal and marine geography. In: GAILE, G. L.; WILLMOTT, C. J. (eds.). Geography in America at the dawn of the 21first century. New York: Oxford University Press, 2006. 842p.

RAABE, A. L. A.; KLEIN, A. H. F.; GONZÁLEZ, M.; MEDINA, R. MEPBAY; SMC: Software tools to support different operational levels of headland-bay beach in coastal engineering projects. Coastal Engineering, v. 57, n. 2, p. 213-226, 2010. Disponível em: <https://ac.elscdn.com/S037838390900146X/1-s2.0-S037838390900146X-main.pdf?_tid=5b9614f0-50dd452e-817c-16d20db400c0\&acdnat=1522532715_c69caf41169ca14661e0c262473c5fb8>. Acesso em: 31 mar. 2018.

RUELLAN, F. A evolução geomorfológica da Baía de Guanabara e regiões vizinhas. Revista Brasileira de Geografia, v. 6, n. 4, p.443-508, 1944. Disponível em: <https://biblioteca.ibge.gov.br/visualizacao/periodicos/115/rbg_1944_v6_n4.pdf>. Acesso em: 31 mar. 2018. 
SALGADO, A. A. R.; BIAZINI, J.; HENNIG, S. Geomorfologia brasileira: panorama geral da produção nacional no início do século XXI (2001-2005). Revista Brasileira de Geomorfologia, v. 9, n. $1, \quad$ p. 85-91, $2008 . \quad$ Disponível em: <http://www.lsie.unb.br/rbg/index.php/rbg/article/view/104>. Acessado em: 30 mar. 2018.

SALGADO A. A. R.; LIMOEIRO, B. F. Geomorfologia brasileira: panorama geral da produção nacional de alto impacto no quinquênio entre 2011-2015. Revista Brasileira de Geomorfologia (Online), São Paulo, v. 18, n. 1, p.225-236, jan-mar, 2017. Disponível em: <http://www.lsie.unb.br/rbg/index.php/rbg/article/view/1154>. Acesso em: 30 mar. 2018.

SANTOS, J. H. S. Lençóis Maranhenses atuais e pretéritos: um tratamento espacial. Tese (Doutorado em Geografia) - Universidade Federal do Rio de Janeiro, Programa de PósGraduação em Geografia, 2008.

SANTOS, J. H. S.; SANTOS, N. F. B. The Lençóis Maranhenses: A paradise of dunes and ponds. In: VIEIRA, B. C., SALGADO, A. A. R.; SANTOS, L. J. C. (Orgs.). Landscapes and Landforms of Brazil. v. 1. New York: Springer, 2015. p.79-90.

SAUERMANN, G.; ANDRADE, J. S.; MAIA, L. P.; COSTA, U. M. S.; ARAÚJO, A. D.; HERRMANN, H. J. Wind velocity and sand transport on a barchan dune. Geomorphology, v. 54, n. 3-4, p. 245-255, 2003. Disponível em: <https://ac.els-cdn.com/S0169555X02003598/1-s2.0S0169555X02003598-main.pdf?_tid=365d2037-8933-4b42-96a7c63504c08c78\&acdnat=1522533411_3ae4c220e828b41080582e96c35aa54f>. Acesso em: 31 mar. 2018.

SCHAEFFER-NOVELLI, Y.; CINTRÓN-MOLERO, G.; CAMARGO, R. R. A. T; CAMARGO, T. M. Variability of mangrove ecosystems along the Brazilian coast. Estuaries, v. 13 (2), p. 204218, 1990.

SERAFIM, M. B.; BONETTI, J. Vulnerabilidade das praias do Estado de Santa Catarina a eventos de erosão e inundação costeira: proposta metodológica baseada em um índice multicritério. Quaternary and Environmental Geosciences, v. 8, n. 2, p. 36-54, 2017. Disponível em: <http://revistas.ufpr.br/abequa/article/view/47281/33966>. Acesso em: 23 mar. 2018.

SHORT, A. D.; Klein, A. H. F. Brazilian Beach Systems. 1. ed. Switzerland: Springer International Publishing Switzerland, 2016. 611 p. Disponível em: <http://www.cerfjcr.org/index.php/research-news-announcements/coastal-research-library-crl/brazilian-beachsystems>. Acesso em: 31 mar 2018.

SILVEIRA, A. D. Morfologia do litoral. In: AZEVEDO, A. Brasil a terra e o homem. As bases físicas. v.1. São Paulo: Companhia Editora Nacional, 1964. p. 253-305.

SILVEIRA, L. F.; Klein, A. H. F.; TESSLER, M. G. Headland-bay beach planform stability of Santa Catarina State and of the northern coast of São Paulo State. Brazilian Journal of Oceanography (Impresso), v. 58, p. 101-122, 2010.

SUGUIO, K.; MARTIN, L. Progress in research on Quaternary sea-level and coastal evolution in Brazil, Holocene sea-level fluctuations, magnitude and causes. IGCP Project 61 (The sealevel program). Columbia: IGP Proceedings, 1981. p. 166-191. 
SUGUIO, K.; MARTIN, L.; BITTENCOURT, A. C. S. P.; DOMINGUES, J. M. L.; FLEXOR J-M. Flutuações do nível relativo do mar durante o Quaternário superior ao longo do litoral brasileiro e suas implicações na sedimentação costeira. Revista Brasileira de Geociências, v. 15, n. 4, p. 273-286, 1985.

SUHAYDA, J. N.; HSU, S. A.; ROBERTS, H. H.; SHORT, A. D. Documentation and analysis of coastal processes, Northeast coast of Brazil. Coastal Studies Institute, Louisiana State University, Baton Rouge. Louisiana: Technical Report n. 238, 1977. 98 p.

SWIFT, D. J. P. Coastal sedimentation. In: STANLEY, D.J.; SWIFT, D.J.P. (Eds.). Marine sediment transport and environmental management, John Wiley \& Sons, p.255-310, 1986.

TELLES, D. H. Q. Marinas e náutica no litoral brasileiro: aportes metodológicos introdutórios para a pesquisa e o planejamento territorial do turismo. El Periplo Sustentable, v. 25, p. 103134, 2013. Disponível em: <http://www.redalyc.org/articulo.oa?id=193427016006>. Acesso em: 31 mar. 2018.

. Escalas do meio náutico e a mediação territorial no Brasil: reflexões sobre o turismo em marinas angrenses. Geosul, v. 30, n. 59, p. 67, 2015. Disponível em: $<$ https://periodicos.ufsc.br/index.php/geosul/article/view/2177-5230.2015v30n59p67>. Acesso em: 30 mar. 2018.

TOLDO JR., E. E.; DILLENBURG, S. R.; ALMEIDA, L. E. S. R.; TABAJARA, L. L.; MARTINS, R. R.; CUNHA, L. O. B. P. Parâmetros morfodinâmicos da praia de Imbé, RS. Pesquisas em Geociências, Porto Alegre (RS), v. 20, n. 1, p. 27-32, 1993.

TOMAZELLI, L. J. Contribuição ao estudo dos sistemas deposicionais holocênicos do nordeste da Província Costeira do Rio Grande do Sul - com ênfase no sistema eólico. Tese (Doutorado) - Universidade Federal do Rio Grande do Sul, Instituto de Geociências, 1990.

. O regime de ventos e a taxa de migração das dunas eólicas costeiras do Rio Grande do Sul, Brasil. Pesquisas em Geociências (UFRGS), Porto Alegre, v. 20, n. 1, p. 18-26, 1993.

- Morfologia, organização e evolução do campo eólico costeiro do litoral norte do Rio Grande do Sul, Brasil. Pesquisas em Geociências (UFRGS), Porto Alegre, v. 21, n. 1, p. 64-71, 1994.

TRICART, J. Problemas geomorfológicos do litoral oriental do Brasil. Boletim Baiano de Geografia, v. 1, n. 1, p.5-39, 1960.

TSOAR, H.; LEVIN, N; MAIA, L. P.; HERRMANN, H. J.; SALES, V. C. The effect of climate change on the mobility and stability of coastal sand dunes in Ceará State (NE Brazil). Quaternary Research (Print), v. 71, p. 217-226, 2009.

TURCQ, B.; MARTIN, L.; FLEXOR, J. M. ; PIERRE, C.; TASAYACO-ORTEGA, L. Origin and evolution of the Quaternary Coastal plain between Guaratiba and Cabo Frio, State of Rio de Janeiro, Brazil. In: KNOPPERS; BIDONE, E.; LACERDA, L. D. (org.). Environmental Geochemistry of Coastal Lagoon Systems of Rio de Janeiro, Brazil. Niterói: 1999. p.25-46.

VALLEGA, A. The regional approach to the ocean, the ocean regions, and ocean regionalisation a post-modern dilemma. Ocean \& Coastal Management, v. 45, p. 721-760, 2002. Disponí- 
vel em: <https://ac.els-cdn.com/S0964569102001047/1-s2.0-S0964569102001047main.pdf?_tid=fe83b163-f0e2-479b-acae-

ee664a0a21b1\&acdnat=1522451785_9c24b110f3ee71bf02a605777c02b71c>. Acesso em: 30 mar. 2018.

VARGAS, A.; RAABE, A. L. A.; KLEIN, A. H. F. Sistema computacional para aplicação do modelo parabólico de praias de enseada. Revista Brasileira de Geomorfologia, v. 3, n. 1, p. 11-19, 2002. Disponível em: <http://www.lsie.unb.br/rbg/index.php/rbg/article/view/11>. Acesso em: 30 mar. 2018.

VIANNA, L. F. N.; BONETTI, J.; POLETTE, M. Gestão costeira integrada: análise da compatibilidade entre os instrumentos de uma política pública para o desenvolvimento da maricultura e um plano de gerenciamento costeiro no Brasil. Revista de Gestão Costeira Integrada, v. 12, n. 3, p. 357-372, 2012. Disponível em: <http://www.aprh.pt/rgci/pdf/rgci-335_Vianna.pdf>. Acesso em: 31 mar. 2018.

VILLWOCK, J. A. (1994). A costa brasileira: geologia e evolução. Notas Técnicas, v. 7. Porto Alegre (RS): CECO/IG/UFRGS, 1994. p. 38-49.

VINTEM, G.; TOMAZELLI, L. J.; KLEIN, A. H. F.. The effect of sand grain size in the aeolian transport processes of transgressive dune fields of the coast of Santa Catarina State, Brazil. Journal of Coastal Research, v. SI 39, p. 102-106, 2006.

WRIGHT, L. D.; SHORT, A. D. Morphodynamic variability of beaches and surf zones, a synthesis. Marine Geology, v. 56, n. 1-4, p.93-118, 1984. Disponível em: <https://www.sciencedirect.com/science/article/pii/0025322784900082>. Acesso em: 31 mar. 2018.

XAVIER-DA-SILVA, J.; PEREIRA, M. L. F.; MARQUES, J. S.; MUEHE, D.; AMADOR, E. S. Análises da variação granulométrica de sedimentos na Barra da Tijuca. Revista Brasileira de Geografia, Rio de Janeiro, v. 35, n. 1, p. 105-139, 1973a. Disponível em: $<$ https://biblioteca.ibge.gov.br/visualizacao/periodicos/115/rbg_1973_v35_n1.pdf>; Acesso em: 31 mar. 2018.

XAVIER-DA-SILVA, J. Processes and landforms in the South American coast. Tese (Doutorado) Louisiana State University and Agricultural and Mechanical College, 1973b. 103p.

YASSO, W. E. Plan geometry of headland-bay beaches. The Journal of Geology, v. 73, n. 5, p. 702-714, $1965 . \quad$ Disponível em: <https://www.jstor.org/stable/30079652?seq=1\#page_scan_tab_contents>. Acesso em: 31 mar. 2018.

ZEMBRUSCKI, S. G. Geomorfologia da margem continental sul brasileira e das bacias oceânicas adjacentes. In: Geomorfologia da margem continental brasileira e das áreas oceânicas adjacentes. Série Projeto REMAC, n.7. Rio de Janeiro: PETROBRÁS; CENPES; DINTEP, 1979. p. 129-177. 